\title{
Intercomparison of four different in-situ techniques for ambient formaldehyde measurements in urban air
}

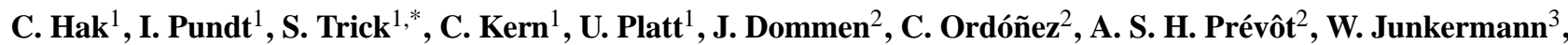 \\ C. Astorga-Lloréns ${ }^{4}$, B. R. Larsen ${ }^{4}$, J. Mellqvist ${ }^{5}$, A. Strandberg ${ }^{5}$, Y. Yu ${ }^{5}$, B. Galle ${ }^{5}$, J. Kleffmann ${ }^{6}$, J. C. Lörzer ${ }^{6}$, \\ G. O. Braathen ${ }^{7}$, and R. Volkamer ${ }^{8}$ \\ ${ }^{1}$ Institute of Environmental Physics (IUP), University of Heidelberg, Germany \\ ${ }^{2}$ Laboratory of Atmospheric Chemistry, Paul Scherrer Institut (PSI), Villigen, Switzerland \\ ${ }^{3}$ Research Centre Karlsruhe, Institute for Meteorology and Climate Research - IFU, Garmisch-Partenkirchen, Germany \\ ${ }^{4}$ Institute for Environment and Sustainability, European Commission Joint Research Centre (JRC), Ispra, Italy \\ ${ }^{5}$ Department of Radio and Space, Chalmers Univ. of Technology (CTH), Göteborg, Sweden \\ ${ }^{6}$ Physikalische Chemie/FB C, Bergische Universität Wuppertal (BUW), Germany \\ ${ }^{7}$ Norwegian Institute for Air Research, Kjeller, Norway \\ ${ }^{8}$ Dept. of Earth, Atmospheric, and Planetary Sciences, Massachusetts Institute of Technology, Cambridge, USA \\ *now at: Department of Atmospheric and Oceanic Sciences, University of California, Los Angeles, USA
}

Received: 23 February 2005 - Published in Atmos. Chem. Phys. Discuss.: 9 May 2005

Revised: 5 August 2005 - Accepted: 19 October 2005 - Published: 2 November 2005

\begin{abstract}
Results from an intercomparison of several currently used in-situ techniques for the measurement of atmospheric formaldehyde $\left(\mathrm{CH}_{2} \mathrm{O}\right)$ are presented. The measurements were carried out at Bresso, an urban site in the periphery of Milan (Italy) as part of the FORMAT-I field campaign. Eight instruments were employed by six independent research groups using four different techniques: Differential Optical Absorption Spectroscopy (DOAS), Fourier Transform Infra Red (FTIR) interferometry, the fluorimetric Hantzsch reaction technique (five instruments) and a chromatographic technique employing C18-DNPH-cartridges (2,4-dinitrophenylhydrazine). White type multi-reflection systems were employed for the optical techniques in order to avoid spatial $\mathrm{CH}_{2} \mathrm{O}$ gradients and ensure the sampling of nearly the same air mass by all instruments. Between 23 and 31 July 2002, up to 13 ppbv of $\mathrm{CH}_{2} \mathrm{O}$ were observed. The concentrations lay well above the detection limits of all instruments. The formaldehyde concentrations determined with DOAS, FTIR and the Hantzsch instruments were found to agree within $\pm 11 \%$, with the exception of one Hantzsch instrument, which gave systematically higher values. The two hour integrated samples by DNPH yielded up to $25 \%$ lower concentrations than the data of the continuously measuring instruments averaged over the same time period. The
\end{abstract}

Correspondence to: C. Hak

(claudia.hak@iup.uni-heidelberg.de) consistency between the DOAS and the Hantzsch method was better than during previous intercomparisons in ambient air with slopes of the regression line not significantly differing from one. The differences between the individual Hantzsch instruments could be attributed in part to the calibration standards used. Possible systematic errors of the methods are discussed.

\section{Introduction}

Formaldehyde $\left(\mathrm{CH}_{2} \mathrm{O}\right)$ is an important and highly reactive compound present in all regions of the atmosphere, arising from the oxidation of biogenic and anthropogenic hydrocarbons. As an intermediate in the oxidation of hydrocarbons to carbon monoxide (CO), formaldehyde plays a primary role in tropospheric chemistry. Reactions of $\mathrm{CH}_{2} \mathrm{O}$ with the hydroxyl radical OH (R1) and photolysis (R2, R3) are the main loss processes (Lowe and Schmidt, 1983):

$$
\begin{aligned}
& \mathrm{CH}_{2} \mathrm{O}+\mathrm{OH} \rightarrow \mathrm{H}_{2} \mathrm{O}+\mathrm{HCO} \\
& \mathrm{CH}_{2} \mathrm{O}+h v \rightarrow \mathrm{H}_{2}+\mathrm{CO} \quad(\lambda<360 \mathrm{~nm}) \quad \mathrm{J}_{\text {molecular }}=4 \cdot 10^{-5} \mathrm{~s}^{-1} \\
& \mathrm{CH}_{2} \mathrm{O}+h v \rightarrow \mathrm{H}+\mathrm{HCO} \quad(\lambda<325 \mathrm{~nm}) \quad J_{\text {radical }}=3 \cdot 10^{-5} \mathrm{~s}^{-1}
\end{aligned}
$$


Losses through dry and wet deposition may also be significant. The lifetime of formaldehyde regarding the major chemical and physical removal pathways is of the order of a few hours in the troposphere (Possanzini et al., 2002). Typical photolysis frequencies $\mathbf{J}_{r}$ and $\mathbf{J}_{m}$ as measured at local noon (11:00 $\left.\mathrm{UTC}, \mathrm{SZA}=26^{\circ}\right)$ during the campaign at Bresso are given above. Since $\mathrm{HCO}$ reacts with $\mathrm{O}_{2}$ to form $\mathrm{CO}+\mathrm{HO}_{2}$ (R5), the rapid gas-phase destruction processes (R1-R3) lead to the production of $\mathrm{CO}$. Through its second photolytic pathway (R3), $\mathrm{CH}_{2} \mathrm{O}$ serves as a major primary source of the hydroperoxyl radical $\left(\mathrm{HO}_{2}\right)$ by way of the following reactions:

$\mathrm{H}+\mathrm{O}_{2}+\mathrm{M} \rightarrow \mathrm{HO}_{2}+\mathrm{M}$

$\mathrm{HCO}+\mathrm{O}_{2} \rightarrow \mathrm{HO}_{2}+\mathrm{CO}$

In the presence of sufficient amounts of nitrogen oxides, the produced odd hydrogen radicals $\left(\mathrm{HO}_{\mathrm{x}}\right)$ result in the formation of tropospheric ozone $\left(\mathrm{O}_{3}\right)$ by converting $\mathrm{NO}$ to $\mathrm{NO}_{2}$, thus providing $\mathrm{OH}$ radicals and leading to subsequent $\mathrm{O}_{3}$ generation (Cantrell et al., 1990). Consequently, $\mathrm{CH}_{2} \mathrm{O}$ plays an important role in local $\mathrm{O}_{3}$ and $\mathrm{OH}$ photochemistry. It is a key component in our understanding of the oxidising capacity of the atmosphere.

Formaldehyde constitutes the most abundant carbonyl compound in both urban areas and the remote troposphere. Levels in the order of 100-500 pptv are common in clean marine environments (e.g. Heikes, 1992; Junkermann and Stockwell, 1999). Typical concentrations in remote continental locations range from a few hundred pptv to more than $1 \mathrm{ppbv}$, whereas 3-45 ppbv are observed regularly in the polluted air of major cities (e.g. Tanner and Meng, 1984; Grosjean, 1991). Concentrations of more than 100 ppbv can reportedly cause irritation of the eyes, nose, and throat. Even higher concentrations of $\mathrm{CH}_{2} \mathrm{O}$ lead to headaches and dizziness (NRC, 1980). In addition, formaldehyde is an air toxic classified as potentially carcinogen (Lawson et al., 1990).

The main source of formaldehyde globally and in the remote background troposphere is its secondary formation by the oxidation of methane $\left(\mathrm{CH}_{4}\right)$ through the hydroxyl radical $(\mathrm{OH})$ (Lowe and Schmidt, 1983). Especially during summer months, the oxidation of various anthropogenic and biogenic hydrocarbons as a result of intense sunlight contributes significantly to its formation (NRC, 1991) in the planetary boundary layer over the continents. In rural areas with dense vegetation, biogenic volatile organic compounds (B-VOCs) are often the dominant precursors. For example, isoprene and terpene oxidation initiated by reactions with either $\mathrm{OH}$ or $\mathrm{O}_{3}$ efficiently forms formaldehyde along with several other key atmospheric species (Duane et al., 2002; Calogirou et al., 1999). Besides secondary production, formaldehyde is also primarily emitted. In urban air, the direct emission of $\mathrm{CH}_{2} \mathrm{O}$ by motor vehicles may contribute significantly to atmospheric concentration levels. The release from industrial processing and biomass burning also make up important primary sources (Carlier et al., 1986). Small amounts of formaldehyde can be emitted directly by vegetation (Kesselmeier et al., 1997).

Accurate formaldehyde measurements are therefore crucial for our understanding of the overall tropospheric chemistry associated with hydrocarbon oxidation, the mechanisms involving the cycling among odd hydrogen species $\left(\mathrm{HO}_{\mathrm{x}}\right)$ and odd nitrogen species $\left(\mathrm{NO}_{\mathrm{x}}\right)$, and the global budgets of $\mathrm{OH}$ and $\mathrm{CO}$. The gained knowledge about formaldehyde will be of great value in validating and refining tropospheric chemistry models as well as in validating satellite measurements of $\mathrm{CH}_{2} \mathrm{O}$. The measurement of formaldehyde is also important from a public health point of view. It is therefore necessary to obtain a better understanding of the causes of differences between the various measurement techniques and to try to reduce the disagreement between them.

Several independent techniques for the detection of formaldehyde with different time resolutions and detection limits have become available over the last two decades. The most common techniques currently applied for measurements of atmospheric formaldehyde comprise spectroscopic, chromatographic, and fluorimetric methods. In contrast to the chromatographic and fluorimetric methods which continuously extract formaldehyde from the air, the spectroscopic techniques are non-destructive. Vairavamurthy et al. (1992) presented an overview of the various methods used for the measuring of atmospheric formaldehyde until then. It should be pointed out that different optical setups are in use for active remote sensing methods (DOAS, FTIR). Results obtained with the long path setup are averages over a light path of several km. For in-situ measurements, a folded light path arrangement (e.g. White system; White, 1976) was developed. It combines the advantage of a long optical absorption path to attain adequate sensitivity with a small measurement volume to allow for comparison with other in-situ measurements.

Despite its importance and the relatively large number of different measurement techniques employed, there is still considerable uncertainty in ambient measurements of formaldehyde. A number of direct intercomparison experiments have been performed, and $\mathrm{CH}_{2} \mathrm{O}$ measurements have been included into air chemistry related field campaigns like BERLIOZ (BERLIn OZone experiment) 1998 (VolzThomas et al., 2003), PIPAPO (PIanura PAdana Produzione di Ozono) 1998 (Neftel et al., 2002), SOS (Southern Oxidants Study) 1995 (Lee et al., 1998). The data from these campaigns and intercomparisons indicate that there is still significant disagreement between the individual techniques. In the following, a summary of previous formaldehyde intercomparisons between various combinations of the techniques applied in the present study is given (also see Table 6).

- Kleindienst et al. (1988) compared five techniques to analyse $\mathrm{CH}_{2} \mathrm{O}$ mixtures in zero air, photochemical mixtures inside a smog chamber, and ambient air in a 
semi-rural area. In the zero air experiment, the average of all the techniques was used as a reference. The values obtained by the Hantzsch as well as the DNPH were systematically higher than the overall average by $21 \%$ and 6\%, respectively. For the measurements in ambient air, a comparison between the DNPH with an enzymatic $\mathrm{CH}_{2} \mathrm{O}$ monitor and a TDLAS (Tuneable Diode Laser Absorption Spectroscopy) instrument yielded a correlation of $\mathrm{r}=0.91$, but only 6 and 10 data points were taken, respectively. The Hantzsch was in a preliminary state of development and therefore not included. The disagreement between the techniques was attributed to calibration differences.

- An intercomparison performed by Lawson et al. (1990) in urban ambient air included DOAS and FTIR White systems, Hantzsch, DNPH, TDLAS, and an enzymatic fluorimetric technique. The average of the spectroscopic techniques was used as the reference. The Hantzsch technique produced values $25 \%$ lower than the spectroscopic average, the DNPH values were 15$20 \%$ lower. The slopes of the regression lines were 0.74 and 0.75 , respectively (correlation $r=0.7-0.9$ ). The main conclusions were that good agreement was observed between the spectroscopic techniques and that differences with the Hantzsch technique were caused by a decrease in the efficiency of the scrubber.

- A study carried out at low formaldehyde concentrations of below $2 \mathrm{ppbv}$ is reported by Trapp and de Serves (1995), who compared results from Hantzsch and DNPH-cartridges technique taken in the tropics. The slope of the regression line was close to unity $(b=1.02)$ and the coefficient of determination between the two techniques was $r^{2}=0.80(r=0.89)$.

- Gilpin et al. (1997) conducted an intercomparison experiment with four continuous methods and two cartridge methods. The experiment employed spiked mixtures and ambient air. In ambient air, the Hantzsch results were $36 \%$ higher than TDLAS, which was used as a reference. Absolute gas standards were used in this study. The differences observed between the TDLAS and the other techniques were attributed to calibration differences and collection efficiencies of the coils and diffusion scrubbers used by some of the participants. They recommended carrying out in-situ calibrations with gas-phase standards introduced at the instruments' air inlets.

- Jiménez et al. (2000) report on measurements taken in the Milan metropolitan area during the LOOP/PIPAPO field experiment in May/June 1998. Results obtained with a commercial long path DOAS (DOAS 2000) and a DNPH-sampler were compared. For the seven days of concurrent measurements, the slope and intercept of the
DOAS vs. the DNPH were 0.78 and $1.96 \mathrm{ppbv}(r=0.32)$. Due to a total optical path of only $425.2 \mathrm{~m}$, the detection limit of the DOAS was high (around $3.75 \mathrm{ppbv}$ ). DOAS results were also compared to predictions by a 3-D Eulerian photochemical model.

- Cárdenas et al. (2000) compared long path (LP) DOAS instruments, Hantzsch and TDLAS at a clean maritime site (Mace Head, Ireland) and a semi-polluted site (Weybourne, United Kingdom). They report correlation coefficients of $r=0.67\left(r^{2}=0.45\right)$ between an LPDOAS and a Hantzsch at Mace Head $\left(\mathrm{CH}_{2} \mathrm{O}\right.$ levels below 1 ppbv) after eliminating outliers, with the Hantzsch measuring higher values (slope $b=0.62$ ). At levels of up to 4 ppbv measured at Weybourne, the agreement between two different LP-DOAS instruments and a Hantzsch was improved, with $r^{2}=0.67$ and 0.82 , respectively. The Hantzsch measured higher values than both LP-DOAS instruments ( $b=0.44$ and 0.13 ). The coefficient of determination for both DOAS instruments was $r^{2}=0.50$. One DOAS instrument measured significantly higher values than the other, with a slope of 0.36 . There was good agreement between TDLAS and Hantzsch for indoor measurements $\left(b=0.85, r^{2}=0.94\right)$.

- Pätz et al. (2000) measured formaldehyde with TDLAS and Hantzsch during a field campaign at Schauinsland mountain. The concentrations measured by both instruments were very close to the theoretical concentration of the employed reference gas. The comparison in ambient air was carried out on a cloudy day with little photochemical activity. The average difference between the two instruments was $0.22 \mathrm{ppbv}$ at an average mixing ratio of 2 ppbv.

- Volkamer et al. (2002) show results of a $\mathrm{CH}_{2} \mathrm{O}$ comparison of a Hantzsch monitor and a DOAS White cell at formaldehyde levels between 25 and $100 \mathrm{ppbv}$. The experiment was conducted in April 2002 in the EUPHORE smog chamber under well controlled experimental conditions during a toluene oxidation experiment. The agreement was within $10 \%$ (slope of regression line $=0.89$ ), with the Hantzsch measuring the higher values. The standard from IFU was employed for calibration. The DOAS calibration was based on the cross-section by Cantrell et al. (1990). The agreement in the presence of photooxidation products from toluene oxidation indicates that cross-interferences are unlikely to be a major error source in either technique.

- Klemp et al. (2003) report on a comparison of a commercial Hantzsch system and a TDLAS. The measurements were performed in the framework of the EVA experiment at a site located in the city plume of Augsburg, Germany. Good agreement within 5\% between 
both methods was observed during photochemically inactive conditions $\left(b=1.05, r^{2}=0.83\right)$. For heavily polluted events with ongoing photochemistry, the Hantzsch measurements exceeded those of the TDLAS by a factor of up to two $\left(b=1.81, r^{2}=0.71\right)$. Calibration errors and negative interferences of the TDLAS were ruled out as reasons for the observed deviations. Positive interferences of the Hantzsch remained among the possibilities.

- During the BERLIOZ field campaign, formaldehyde was measured by an LP-DOAS and a Hantzsch monitor (AL4001) at a rural site in Pabstthum, Germany (Grossmann et al., 2003). The mixing ratios measured by the LP-DOAS were systematically larger. The regression analysis of the two data sets yielded a slope of 1.23 on average $\left(r^{2}=0.66\right)$. During days with high photochemical activity, however, the difference was a factor of 1.7. Differences of even higher magnitude were observed at the BERLIOZ sites Eichstädt and Blossin (Volz-Thomas et al., 2003) during an intensive measurement period. The discrepancies could not be resolved. The cross-section by Meller and Moortgat (2000) was used for the DOAS calibration.

- Measurements utilising FTIR and DOAS White systems, Hantzsch and DNPH-cartridge methods were carried out in the EUPHORE smog chamber in Valencia as part of the European project DIFUSO. The experiments were conducted at different concentration levels of formaldehyde, and under very different experimental conditions, e.g. with diesel exhaust in the dark or with mixtures of diesel exhaust and different hydrocarbons under irradiation with sunlight. For concentrations below $5 \mathrm{ppbv}$, i.e. close to the detection limit of the DOAS in EUPHORE, the DOAS method yielded systematically higher values than the Hantzsch monitor, whereas the FTIR had values comparable to the Hantzsch. For concentrations between $10 \mathrm{ppbv}$ and $100 \mathrm{ppbv}$, the agreement between all methods was very good (J. Kleffmann, personal communication).

In summary, during past intercomparison campaigns, the level of agreement varied from good to quite poor, with no obvious pattern being discernible. To effectively compare insitu techniques with long path instruments one must keep in mind that spatial gradients of $\mathrm{CH}_{2} \mathrm{O}$ may occur. Although this problem of probing different air volumes can be avoided by using multi-reflection systems (e.g. White system), only one such comparison study has been published to date (Lawson et al., 1990; see above). The significant differences $( \pm 25 \%)$ were attributed to instrumental problems. The FTIR method was rarely used in the past for $\mathrm{CH}_{2} \mathrm{O}$ measurements in ambient air.

Here, an intercomparison of several commonly used techniques for the measurement of formaldehyde is presented. The study was carried out to evaluate differences "between the various techniques" and "among similar instruments". Multi-pass systems were employed for the spectroscopic techniques to ensure probing of the same air volume by all instruments. The assembly included eight instruments working with four independent techniques, including two spectroscopic techniques - Differential Optical Absorption Spectroscopy (DOAS) (Sect. 2.1) and Fourier Transform Infra Red (FTIR) interferometry (Sect. 2.2) -, Hantzsch fluorimetry (Sect. 2.3), and DNPH cartridge sampling (Sect. 2.4). In this intercomparison, the Hantzsch technique was represented by five similar Hantzsch instruments.

\section{Description of participating instruments}

In the following a brief description of the instruments, comparison site and employed procedures is presented. See Table 1 for the detection limits, accuracy and precision of the individual instruments.

\subsection{DOAS White system (IUP)}

A modified version of the open White type multi-reflection system utilising Differential Optical Absorption Spectroscopy (DOAS) (e.g. Platt, 1994) was operated by IUP. The basic White (1976) system was improved for stability by using three quartz prisms that each also double the maximum feasible lightpath of the mirror system (Ritz et al., 1993). The $\mathrm{f} / 100$ mirror system consisted of three spherical concave mirrors of identical focal length - a field mirror and two objective mirrors, which were located at a distance of $15 \mathrm{~m}$ facing the field mirror. The total path length could be varied from $240 \mathrm{~m}$ (16 traversals) up to $2160 \mathrm{~m}$ (144 traverses) by adjusting the objective mirrors (e.g. Ritz et al., 1993). A xenon high-pressure lamp was used as light source. The optics of the White system were optimised for $\mathrm{CH}_{2} \mathrm{O}$ detection, using a set of three dielectric mirrors, each with a reflectivity of $>98 \%$ around $321 \pm 20 \mathrm{~nm}$. The relative adjustment of the two objective mirrors to the field mirror was maintained using a new laser adjustment system (C. Kern, personal communication). Aluminium coated mirrors were used as transfer optics. A $30 \mathrm{~cm}$ Czerny-Turner spectrograph equipped with a 1200 grooves $/ \mathrm{mm}$ reflective grating was used to project the spectral interval from 303 to $366 \mathrm{~nm}$ onto a 1024-element diode array detector (HMT, Rauenberg) which was cooled by a Peltier element to $-13^{\circ} \mathrm{C}$ (dispersion of $0.061 \mathrm{~nm} / \mathrm{pixel}$ ). The temperature of the spectrograph was stabilised to $35 \pm 0.1^{\circ} \mathrm{C}$ in order to reduce temperature drifts. The integration time for individual scans varied between 3-30 s, and several ten scans were typically binned to reduce photon noise. Lamp reference spectra were recorded twice a day at the shortest path $(240 \mathrm{~m})$, and residual absorptions over this reduced light path were characterised and subtracted from the measured spectra. In the spectral analysis procedure atmospheric spectra were corrected for dark 
Table 1. Detection limit, accuracy, precision of all the instruments for the field measurements during the intercomparison campaign as stated by the groups. ${ }^{\mathrm{a}}$ depends on present formaldehyde concentration ( $6 \%$ for 15 ppbv and $27 \%$ for 2 ppbv), ${ }^{b}$ or 150 pptv (whatever is larger), c except IFU 3: 25-29 July.

\begin{tabular}{lllllll}
\hline Instrument / Type & Institute & $\begin{array}{l}\text { Time period } \\
\text { of operation }\end{array}$ & $\begin{array}{l}\text { Det. lim. } \\
\text { [ppbv] }\end{array}$ & Accuracy & Precision & $\begin{array}{l}\text { Time res. } \\
{[\mathrm{min}]}\end{array}$ \\
\hline DOAS White system & IUP & $24 / 07-19 / 08$ & 0.9 & $\pm 6 \%$ & $0.45 \mathrm{ppbv}$ & $1-2$ \\
FTIR White system & CTH & $22 / 07-18 / 08$ & 0.4 & $6-27 \%^{\mathrm{a}}$ & $0.2 \mathrm{ppbv}$ & 5 \\
Hantzsch AL4021 & PSI & $23 / 07-26 / 07$ & 0.15 & $\pm 15 \% \mathrm{~b}$ & $\pm 10 \% \%^{\mathrm{b}}$ & $\sim 1.5$ \\
Hantzsch AL4001 & BUW & $24 / 07-31 / 07$ & 0.15 & $\pm 15 \% \mathrm{~b}$ & $\pm 10 \% \%^{\mathrm{b}}$ & $\sim 1.5$ \\
Hantzsch AL4021 & IFU & $24 / 07-17 / 08^{\mathrm{c}}$ & 0.15 & $\pm 15 \% \mathrm{~b}$ & $\pm 10 \% \%^{\mathrm{b}}$ & $\sim 1.5$ \\
DNPH & JRC & $23 / 07-18 / 08$ & 0.5 & $\pm 10 \%$ & $0.1 \mathrm{ppbv}$ & 120 \\
\hline
\end{tabular}

current and electronic offset and divided by a lamp reference spectrum recorded the same day. The ratio spectrum was high pass filtered by subtracting a triangular-smoothed copy of itself, thereby accounting for small changes in reflectivity near the reflectivity drop-off of the dielectric mirrors as well as Rayleigh and Mie scattering in the atmosphere.

Average trace gas concentrations of $\mathrm{CH}_{2} \mathrm{O}, \mathrm{NO}_{2}, \mathrm{O}_{3}$, and $\mathrm{HONO}$ were retrieved by simultaneously fitting resolutionadjusted reference spectra using the combined linearnonlinear least squares algorithm (e.g. Stutz and Platt, 1996) of the MFC software (Gomer et al., 1995). Formaldehyde was identified by its four strong absorption bands in the UV between 310 and $337 \mathrm{~nm}$, and calibrated using the literature cross-section by Meller and Moortgat (2000).

The stated uncertainty of the formaldehyde UV absorption cross-section is $\pm 5 \%$ (Meller and Moortgat, 2000). Differences between the available $\mathrm{CH}_{2} \mathrm{O}$ cross-sections are discussed in Sect. 4.4. The systematic error of the DOAS spectrometer was determined to be $<3 \%$ as described by Stutz (1996). The total systematic error of the $\mathrm{CH}_{2} \mathrm{O}$ concentrations, determined by the DOAS is therefore $<6 \%$. A mean detection limit of $\mathrm{CH}_{2} \mathrm{O}$ of 0.9 ppbv was determined with an average time resolution of $137 \mathrm{~s}$.

\subsection{FTIR White system (CTH)}

In Fourier-Transform Infra Red (FTIR) interferometry, the absorption of infrared light by various molecules is quantified in the wavelength region between 2 and $15 \mu \mathrm{m}$. The open path FTIR White system was set up by CTH and ran semi-continuously over 28 days, between 22 July and $18 \mathrm{Au}-$ gust. The system consisted of an infrared spectrometer coupled to an open path multi-reflection cell (White cell) with a base path of $25 \mathrm{~m}$ and a total path length of $1 \mathrm{~km}$. The White cell was based on the retroreflector design outlined by Ritz et al. (1993) with minor modifications. An FTIR (BOMEM MB 100) computer-controlled spectrometer with a resolution of $1 \mathrm{~cm}^{-1}$ was employed. A $24 \mathrm{~h}$ dewar InSb detector was used covering the spectral region from 1800 to $3500 \mathrm{~cm}^{-1}$.
During the field campaign, the computer, FTIR spectrometer and field mirror of the FTIR White system were located inside the shipping container which also housed the DOAS system's instrumentation. The objective mirrors of the FTIR White system were located on a tripod $25 \mathrm{~m}$ away from the field mirror. The spectra were analysed using the non-linear fitting software NLM (D. Griffith, personal communication), which is a further development of the MALT code (Griffith, 1996). In NLM, line parameters from the HITRAN compilation (Rothman, 1987) are convolved with appropriate instrument parameters and subsequently least square fitted to the measured spectra to derive the average concentration of various molecules along the measurement path. Formaldehyde was detected employing a characteristic doublet at 2779 and $2781.5 \mathrm{~cm}^{-1}$. During most of the campaign, 64 consecutively recorded spectra were binned, thus yielding a measurement time resolution of $5 \mathrm{~min}$. The measurement precision as obtained from the standard deviation of the $\mathrm{CH}_{2} \mathrm{O}$ measurements is around $0.2 \mathrm{ppbv}$. The overall accuracy, as determined from the uncertainty of 5\% in the spectroscopic data (Rothman et al., 1987), an offset which depends on the $\mathrm{CH}_{2} \mathrm{O}$ concentration and the precision, is specified to vary from $27 \%$ for a measured mixing ratio of 2 ppbv to $6 \%$ for 15 ppbv.

\subsection{Hantzsch fluorimetric monitors (IFU, PSI, BUW)}

This technique is based on sensitive wet chemical fluorimetric detection of $\mathrm{CH}_{2} \mathrm{O}$, which requires the transfer of formaldehyde from the gas phase into the liquid phase. This is accomplished quantitatively by stripping the $\mathrm{CH}_{2} \mathrm{O}$ from the air in a stripping coil with a well defined exchange time between gas and liquid phase. The coil is kept at $10^{\circ} \mathrm{C}$ to ensure a quantitative sampling ( $>98 \%$ ) of $\mathrm{CH}_{2} \mathrm{O}$ even at pressures as low as $600 \mathrm{hPa}$. The gas flow is controlled by a mass flow controller with a precision of $1.5 \%$, and a constant liquid flow is provided by a peristaltic pump. The detection of formaldehyde is based on the so-called "Hantzsch" reaction (Nash, 1953). It employs the fluorescence of 
3,5-diacetyl-1,4-dihydrolutidine (DDL) at $510 \mathrm{~nm}$, which is produced from the reaction of aqueous $\mathrm{CH}_{2} \mathrm{O}$ with a solution containing 2,4-pentanedione (acetylacetone) and $\mathrm{NH}_{3}$ (ammonia). The excitation wavelength is $412 \mathrm{~nm}$. Studies of interferences showed that the technique is very selective for formaldehyde, with the response for other molecules found in typically polluted air masses being several orders of magnitude lower. The technique is described in detail by Kelly and Fortune (1994).

This type of instrument was operated by three groups. The BUW used an Aero Laser $\mathrm{CH}_{2} \mathrm{O}$ analyser, model AL4001, a commercially available instrument. The PSI monitor and the three IFU instruments were new versions of the AL4001, the AL4021, which is identical in the chemistry components, but with slight modifications mainly concerning the temperature stabilisation of the fluorimeter and the layout of the gas flow. All Hantzsch instruments were equipped with the same optical filters. For the sake of brevity, the five instruments used in this intercomparison will be referred to as IFU1, IFU2, IFU3, PSI, and BUW. The time resolution of the instruments was $\sim 90$ s with a delay time $(0-90 \%$ of the final value after a change in concentration) of about 4 min depending on the flow rate settings. The systems were calibrated once per day using liquid standards, which were prepared independently by each group. Zero adjustment was performed once per day (IFU), every six hours (PSI), and about six times per day (BUW), respectively. The Aero Laser instrument had a gas-phase detection limit of $150 \mathrm{pptv}$ in the field. The accuracy and precision are indicated as $\pm 15 \%$ or $150 \mathrm{pptv}$ and $\pm 10 \%$ or $150 \mathrm{pptv}$, respectively. The ozone cross sensitivity is stated to be a positive signal of 200 pptv $\mathrm{CH}_{2} \mathrm{O}$ per 100 ppbv of ozone.

\subsection{DNPH cartridges, HPLC/UV (JRC)}

Carbonyl compounds were measured in two-hour periods during the day to determine their diurnal fluctuation in air.

Sampling was done according to the standard of the European Monitoring network, EMEP (Rembges et al., 1999). The air sample (flow $0.9-1.01 / \mathrm{min}$ ) was drawn through an ozone scrubber (Waters Sep-Pak KI cartridges) before passing into the 2,4-dinitrophenylhydrazine (DNPH) coated C18 cartridges (Waters Sep-Pak DNPH-cartridges). Airborne carbonyls are hereby collected as their non-volatile 2,4dinitrophenylhydrazone derivatives.

The cartridges were eluted with $2.5 \mathrm{ml}$ of acetonitrile in the laboratory, diluted with $2.5 \mathrm{ml}$ of $\mathrm{H}_{2} \mathrm{O}$ and stored at $5^{\circ} \mathrm{C}$ until analysis. The samples were analysed by HPLC-UV (high performance liquid chromatography) with a temperature stabilised $\left(20^{\circ} \mathrm{C}\right) 30 \mathrm{~cm} \times 3.9 \mathrm{~mm} \mathrm{C18}$-coated silica gel $(4 \mu \mathrm{m})$ column (NOVO-PAK) run in the gradient mode $(0.9 \mathrm{ml} / \mathrm{min})$. Detection and quantification were carried out at $360 \mathrm{~nm}$. The employed eluents were $\mathrm{H}_{2} \mathrm{O}$ (A-eluent) and acetonitrile (Beluent). The gradient was programmed from $50 \%$ B to $90 \%$
B in $42 \mathrm{~min}$. The detection limit for this method was in the range of 5-20 ng formaldehyde $(\mathrm{S} / \mathrm{N}=3)$.

A possible interference may be caused by the coelution of hydrazones of target compounds with hydrazones of other aldehydes and ketones. However, for the formaldehydehydrazone no interference has been reported to date. Due to high humidity clogging the sample cartridges during the night and early morning, the automatic sampling system was not used during night time and both the first and the last samples were taken without ozone scrubber. Positive interference in the form of a number of extraneous peaks in the HPLC-UV chromatograms has been reported for C18 DNPH-cartridges, when used at high atmospheric ozone concentrations without ozone scrubber (Vairavamurthy et al., 1992). In the present study, sampling without ozone scrubber was only carried out at low ozone concentrations. Thus, positive interference is unlikely. Moreover, no extraneous peaks were monitored. However, as in all kinds of chromatographic analysis, coelution of unknowns with the target analytes cannot be excluded. In previous studies of ambient air from this area, we have used the DNPH technique at low ozone concentrations without ozone scrubber and have been able to rule out interference from potential coelutants by analysis of the DNPH extracts not only by HPLC-UV but also with HPLC coupled to atmospheric pressure mass spectrometry (Duane et al., 2002).

Blank samples were taken on a daily basis by exposing DNPH cartridges to open air without sample flow. The formaldehyde blank levels were all below $2 \mathrm{nmol} / \mathrm{cartridge}$. For an air volume of 1201 this leads to a detection limit of $0.5 \mathrm{ppbv}$.

\section{Description of the campaign}

The intercomparison measurements were conducted in Bresso (northern Italy) between 23 July and 31 July 2002 as a part of the FORMAT-I campaign. The principal goal of the European project FORMAT "Formaldehyde as a tracer of photooxidation in the troposphere" was to obtain a better knowledge of the regional distribution of formaldehyde and its temporal behaviour in interaction with other major photochemical constituents. This can lead to better prediction of smog episodes and to better quantification of emissions from traffic and biomass burning. The first week of the campaign was used to intercompare both similar instruments and different in-situ techniques, before the instruments were distributed to the other sites within the Po Basin for the remainder of the campaign. Three sites, upwind, urban and downwind of Milan, were chosen along a south to north axis determined by the prevailing daytime wind direction. Bresso was the site representative for urban conditions. Measurements of photooxidants at this site had already been conducted in the LOOP/PIPAPO field experiment 1998 (e.g. Neftel et al., 2002). 


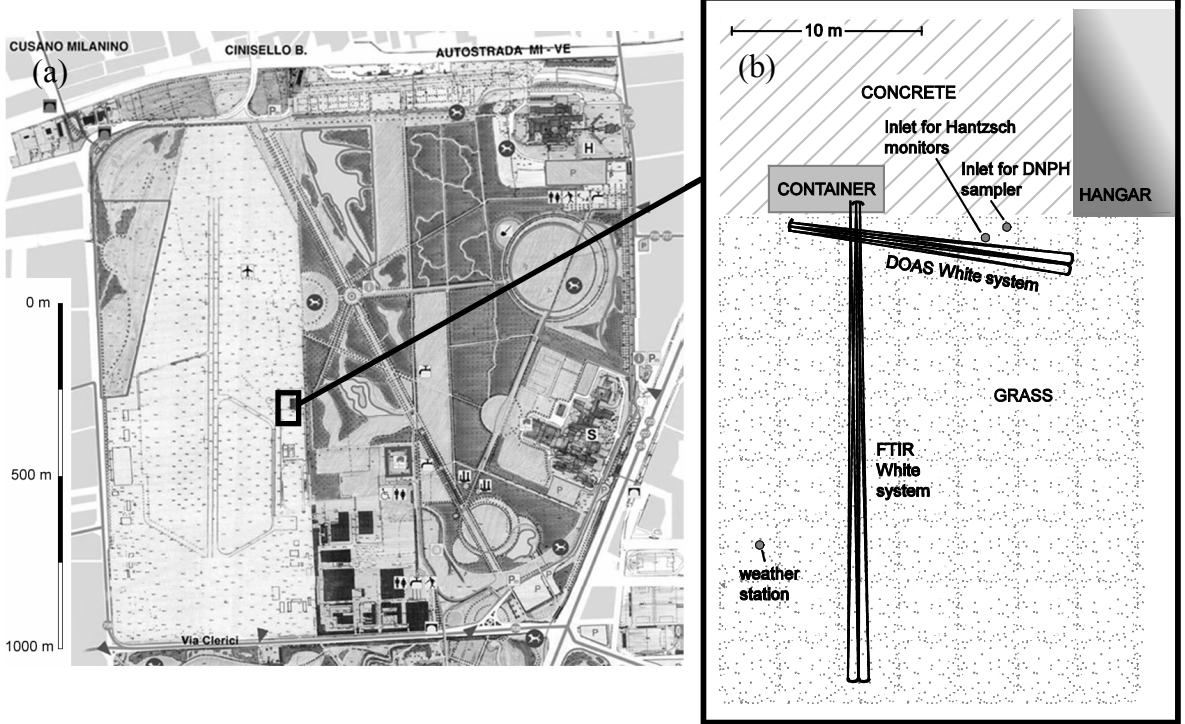

Fig. 1. (a) Surrounding area of the site at Bresso (MI), airfield and Parco Nord. (b) The setup of the instruments is shown on the right hand side.

Bresso (at $45^{\circ} 32.4^{\prime} \mathrm{N}, 9^{\circ} 12.1^{\prime} \mathrm{E}, 146 \mathrm{~m}$ a.m.s.l.) is situated on the northern outskirts of Milan, $5 \mathrm{~km}$ north of the city centre, where vehicular and industrial emissions of $\mathrm{CH}_{2} \mathrm{O}$ can mix with photochemically produced formaldehyde from anthropogenic and biogenic hydrocarbon emissions, so that both primary and secondary sources of $\mathrm{CH}_{2} \mathrm{O}$ are of importance. Possible sources for biogenic hydrocarbons are nearby local parks.

\subsection{The measurement site}

The measurement site was located on the premises of a small airfield (see Fig. 1a). The adjacent $\sim 1.2 \mathrm{~km}^{2}$ in the west were grass-covered. The closest sources for road traffic emissions were a busy street $550 \mathrm{~m}$ to the west (Viale A. Grandi, with an adjacent residential area) and a major motorway (A4 Torino - Venezia) $1000 \mathrm{~m}$ to the north. The Parco Nord, a $\sim 2.2 \mathrm{~km}^{2}$ green recreation area was located directly to the east. Several hundred metres farther to the east, the Viale Fulvio Testi, a main road with high traffic density, leads to the city centre. There are no known emission sources for $\mathrm{CH}_{2} \mathrm{O}$ in the direct surroundings of the site, apart from two lorry events, which are mentioned below.

The physical arrangement of the instruments is sketched in Fig. 1b. A shipping container housed the main mirror of the FTIR and the spectrographs of both White systems. The DOAS main mirror was placed in front of the container. The light paths of the White systems were set up approximately $1.5 \mathrm{~m}$ above the ground with a crossing alignment. For the comparison with the spectroscopic techniques, the sampling ports of the Hantzsch monitors and the DNPH-sampler were mounted close to the intersecting pathways of both multireflection systems in a height of about $1.2 \mathrm{~m}$ above ground and at a distance of a few metres from each other. Thus, sampling of the same air mass can be implied. The Hantzsch monitors were sampling from a $10 \mathrm{~m}$ common PFA inlet line with $4 \mathrm{~mm}$ inner diameter, which lead to a hangar where the Hantzsch instruments were operated. The sampling altitude was $1.2 \mathrm{~m}$ above ground. The inlet line was protected from apparent aerosols by a nuclepore inline filter $(47 \mathrm{~mm}$ diameter, $0.5 \mu \mathrm{m}$ pore size), which was replaced once per day.

In addition to formaldehyde, ozone (up to $85 \mathrm{ppbv}$ ), nitrogen dioxide (up to $40 \mathrm{ppbv}$ ), sulphur dioxide, nitrous acid, carbon monoxide, nitric oxide, other carbonyls and meteorological parameters were measured simultaneously at the site throughout the campaign.

\subsection{Atmospheric conditions during the intercomparison}

During the first half of the intercomparison period, the synoptic situation over Central Europe was affected by a zonal flow in the $500 \mathrm{hPa}$ level. An upper-tropospheric ridge which developed after 27 July and an associated surface high pressure area extending over southern and central Europe governed the second half of the intercomparison week, leading to fair weather conditions. Its impact was superseded by a trough evolving over Ireland which introduced a lowpressure episode after 31 July. A cyclonic flow pattern developed steering low pressure systems on a track passing over Northern Italy.

Measurements of the standard meteorological parameters were performed continuously at the intercomparison site. The temperature during the intercomparison week varied between 17 and $32^{\circ} \mathrm{C}$ with strong diurnal variations. The global radiation reached $800 \mathrm{~W} / \mathrm{m}^{2}$ every day. The conditions were appropriate for moderate photooxidant production. Under 
these conditions, daytime ozone mixing ratios of up to $85 \mathrm{ppbv}$ were measured at the site. The ozone levels dropped to zero due to titration with $\mathrm{NO}$ from local emissions and deposition during the night. The relative humidity reached $75-100 \%$ during several nights and was typically $50-60 \%$ during the day, with an average of $62 \%$ over the complete week. There were no rain events in the greater Milan area during the intercomparison week.

At night and during the early morning hours, the wind (measured at $2 \mathrm{~m}$ height) generally came from the north and wind speeds were low. Calm winds below $3.5 \mathrm{~m} / \mathrm{s}$ with southerly components were observed during the day, beginning in the late morning thus providing air from downtown Milan. This diurnal change of air flow in the Po Basin arises from a mesoscale circulation which is orographically induced by a heat low over the Alps, leading to a southern wind direction during daytime and a flow from north to south during the night.

\section{Results}

\subsection{Intercomparison of ambient measurements}

After the campaign the final formaldehyde data of the individual groups was openly collected and compared. The temporal resolution of the data ranged from two to five minutes for the optical instruments and the Hantzsch monitors (these methods will hence be referred to as "continuous methods"), whereas the DNPH method required two hours for each sample. Due to the different measurement intervals of the various instruments, each of the continuous instruments' data sets was integrated and $30 \mathrm{~min}$ averages were calculated on a common time scale. When compared to the DNPH results, the data was integrated over two hours.

Figure 2 presents the formaldehyde mixing ratio time series as measured (a) by the Hantzsch instruments, and (b) by the optical methods. Because large differences between DOAS and Hantzsch results were found (e.g. Grossmann et al., 2003), (c) shows a direct comparison between DOAS and BUW Hantzsch results. This Hantzsch monitor was operating almost continuously. The time series of two-hour integrated values for each instrument is shown in (d), where the horizontal bars denote the $\mathrm{CH}_{2} \mathrm{O}$ levels and the duration of the DNPH measurement periods.

Ambient mixing ratios between 1 and $13 \mathrm{ppbv}$ (for the $30 \mathrm{~min}$ averages) were detected by all instruments, and the temporal variation was generally in good agreement. However, the observations obtained from the IFU1 instrument are systematically higher than those from all other instruments until 28 July. After that date, IFU1 measured considerably lower concentrations than the other instruments. On 25 and 26 July, a diverging temporal behaviour of IFU2 was observed when compared to all other instruments (Fig. 2a). After 26 July, IFU2 levels are in good agreement with the other
Hantzsch levels. The accordance between the Hantzsch monitors IFU3, PSI and BUW was notably good. However, a slight offset between the results of IFU3 and PSI compared to those of BUW is discernible. The overall agreement between the DOAS measurements and the BUW Hantzsch is good (Fig. 2c). Particularly large offsets between the two methods, as reported in previous comparisons (see Sect. 1), were not detected. Occasionally occurring differences are likely due to local inhomogeneities caused by cars or lorries. For the six days of DNPH measurements during the intercomparison week, the rough temporal variation of the formaldehyde concentration during the day was well described by the two-hour integrated measurements (Fig. 2d). The observed concentration levels agree with those of most of the continuous instruments. The discrepancies mentioned for IFU1 and IFU2 are recognisable here as well.

During the intercomparison week the formaldehyde mixing ratios were comparatively low for an urban site, varying between 1 and $6 \mathrm{ppbv}$ most of the time. Typical $\mathrm{CH}_{2} \mathrm{O}$ mixing ratios around $10 \mathrm{ppbv}$ were reported for the LOOP/PIPAPO campaign 1998 at the same site in Bresso (e.g. Alicke et al., 2002). Five days of the present study exhibit a diurnal pattern with minimum values during night and higher levels during daytime, whereas three consecutive days feature no pronounced diurnal variation and levels of around $4 \mathrm{ppbv}$. Two events of particularly high formaldehyde concentration occurred on 24 July and 30 July. The first event was caused by lorries usually stored in the hangar nearby. During this event, however, they were parked within $100 \mathrm{~m}$ of the measurement site with their engines running idle. This incident gave rise to an experiment conducted on $30 \mathrm{July}$, when the lorries were placed close to the instruments with the diesel engines running. The rapid increase of $\mathrm{CH}_{2} \mathrm{O}, \mathrm{CO}$ and HONO within a few minutes indicates a distinct exhaustgas plume and most probably an inhomogeneous formaldehyde distribution within the probed air mass. Thus, the time series used for the intercomparison do not contain the data points from these two incidents. In the evening of 29 July, a change in the sampling line setup was performed. The inlets of the Hantzsch instruments IFU1, BUW, and IFU2 were mounted at different height levels to measure possible vertical differences in the formaldehyde distribution. Therefore, the Hantzsch instruments were no longer sampling identical air masses, and these data points are not included in the intercomparison either.

The data for the ambient measurements was compared by pairing sets of data for all combinations of instruments for which simultaneous measurements were taken. Linear regressions were calculated for each pair of instruments in order to compare slopes, intercepts, and correlation coefficients. Since both data sets in the regression are subject to error, an ordinary least squares regression is inappropriate. Because only the vertical distances of the data points to the regression line (only y direction) are minimised, the true slope of the regression line is underestimated (Riggs et al., 

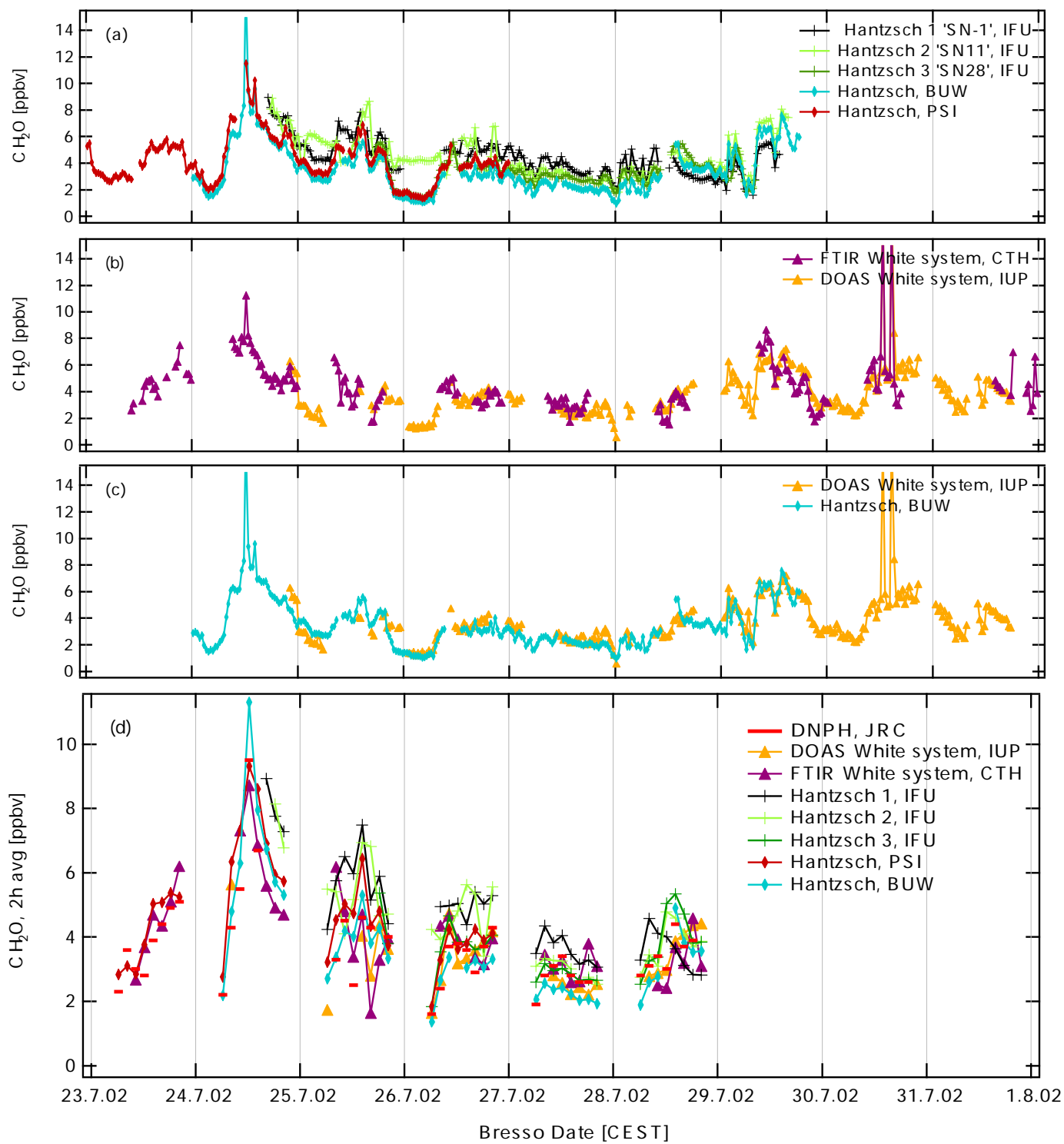

Fig. 2. (a-c) Formaldehyde time series as half hourly averages (ticks at 00:00 Central European Summer Time) at Bresso during the intercomparison week as measured (a) by the five Hantzsch monitors, and (b) by the optical techniques FTIR and DOAS. (c) Direct comparison of the DOAS (yellow triangles) and BUW Hantzsch monitor (blue rhombs) results. Note that the two peaks occurring on 30 July can be attributed to a local lorry emission source initiated by the experimentalists. Those points were omitted for the intercomparison. (d) Formaldehyde measurements by the continuous instruments DOAS, FTIR and Hantzsch (as two hour averages) and DNPH (samples of two hours). The length of the horizontal lines corresponds to the duration of the DNPH measurement periods.

1978). Thus, the regressions were calculated using a method which is often called orthogonal regression. This method minimises the distance in both directions (both $\mathrm{y}$ and $\mathrm{x}$ direction). Individual errors of the data points are accounted for by a weighted line fit described in Press et al. (1992). Scatter plots for almost all pairs of continuous instruments are shown in Fig. 3a-r. The statistical data for all combinations are depicted in the plots and summarised in Table 2. After a modification in the instrument on 28 July, IFU1 measured lower values. The two time periods before and after this modification are considered separately in the following regression analysis, and the markers for the second period are displayed as stars in Fig. 3. After a change in the system on 26 July, the agreement between IFU2 and the other instruments is good. Only the measurements taken after 26 July are considered reliable. Thus, the regression results of IFU2 shown in Table 2 exclude the first two days of operation. 

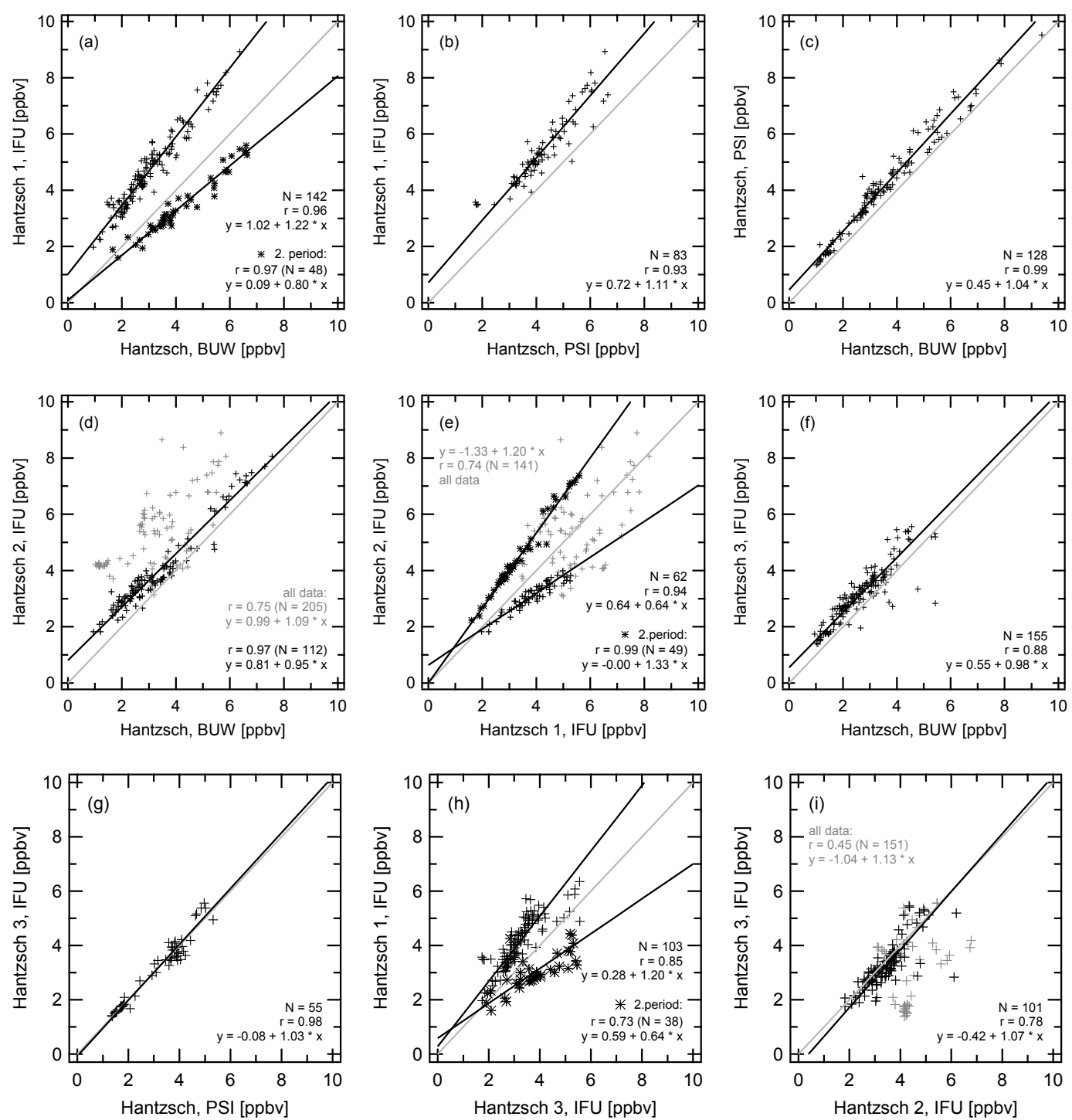

Fig. 3. (a-r) Scatter plots for most pairs of the seven continuously measuring instruments taking part in the intercomparison. $\mathrm{The}^{\mathrm{C}} \mathrm{CH}_{2} \mathrm{O}$ mixing ratios are plotted versus one another for matched times of measurements, and linear regressions were calculated. The solid lines drawn through the data correspond to the weighted orthogonal least squares fit to the data (black) (York, 1966), and the one to one correspondence line (grey), respectively. For the two periods of IFU1 measurements (before and after 28 July 12:00) individual regressions were calculated. Additional grey markers indicate questionable IFU2 data points before 26 July. Regression parameters for the overall data sets and subsets are given in the plots.

\subsubsection{Agreement among the Hantzsch instruments (a)-(i)}

The Hantzsch instruments PSI, BUW, IFU1, and IFU3 correlate very well. The correlation coefficients exceed $r=0.9$ for most combinations (Fig. 3a-g, Table 2). The highest degree of correlation was found between the two Hantzsch instruments PSI and BUW with a correlation coefficient of $r=0.99$ for the three days of simultaneous measurements. The slope of the regression line is near unity $(b=1.04)$, but there is a positive offset of $0.46 \mathrm{ppbv}$ for PSI, significant at the $95 \%$ level. A similar result was found for IFU3 with a slope of $b=0.98$ and an offset of $0.55 \mathrm{ppbv}$ when compared to BUW. IFU3 and PSI agree with a high degree of correlation $(r=0.98)$. The linear regression reveals a slope not significantly different from unity and no offset. However, IFU1 measured systematically higher values for the first period, when compared to IFU3, PSI and BUW, which is evident in the slopes of the regression lines: They are significantly steeper than one and show non-zero intercepts. For the second period, IFU1 measures distinctly lower concentrations than all other instruments. This becomes apparent by the second regression line. 

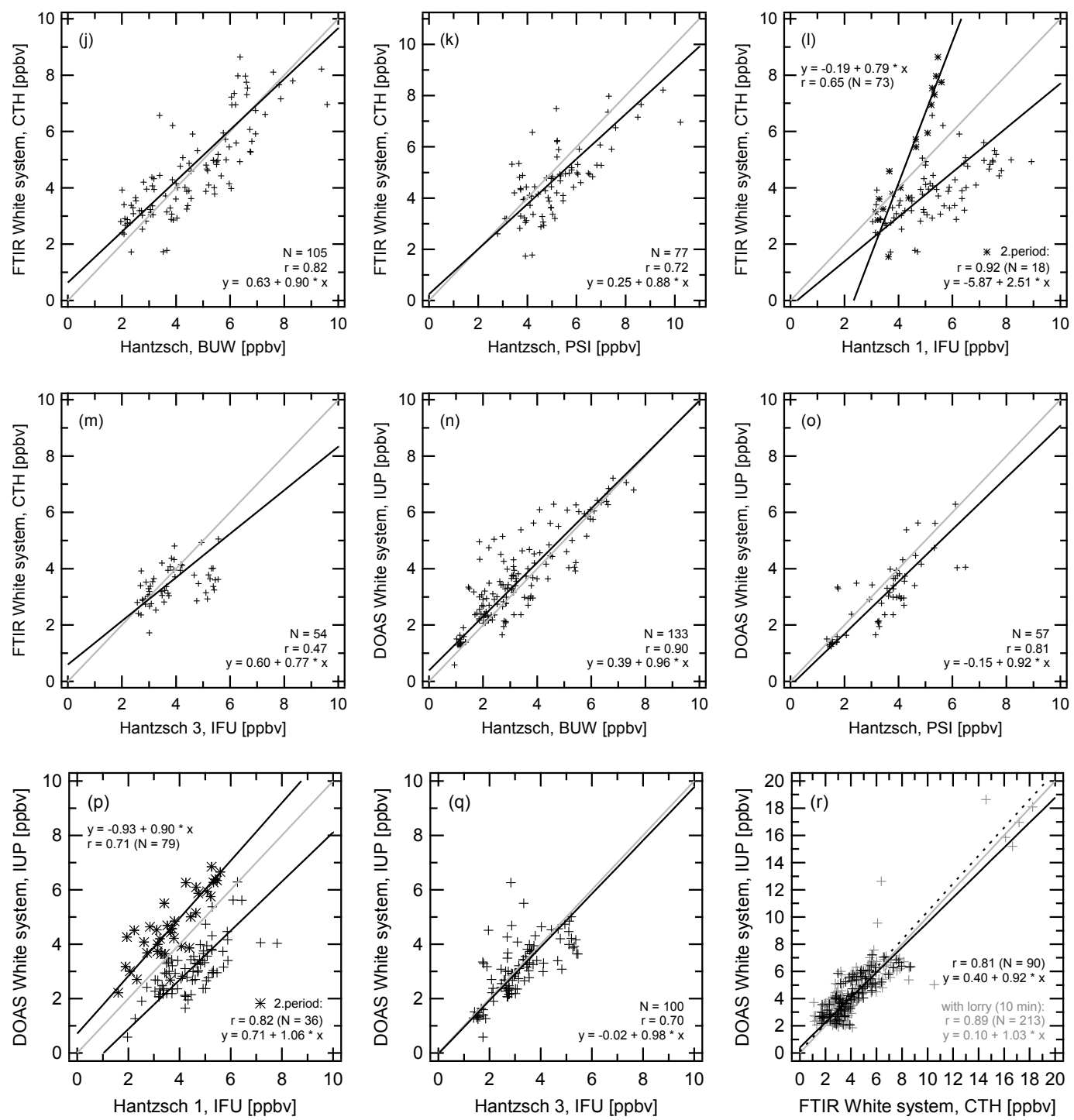

Fig. 3. Continued.

The correlation and regression analysis including IFU2 results shows little agreement with correlation coefficients between 0.45 and 0.75 if one considers the complete IFU2 data set (grey markers). The data points are highly scattered around the regression lines (figures not shown here). The scattering for IFU2 can partly be attributed to the diverging results as a consequence of malfunction of the system on 25 and 26 July (Fig. 2a). If one considers only the reliable IFU2 data points after $26 \mathrm{July}$, there are no mutual points with PSI, but the comparison with BUW yields $r=0.97, b=0.95$, $a=0.81$. IFU1 and IFU2 agreed considerably better after 26 July $(r=0.94)$ than for the entire data set, but with a slope of only $b=0.64$ ( $a=0.64)$, which to some degree matches the previously observed positive bias of IFU1.

Possible reasons for the disagreement among these five nearly identical instruments are discussed in Sect. 4.3.

\subsubsection{Agreement between spectroscopic and Hantzsch techniques (j)-(q)}

The FTIR measurements compare quite well with the BUW Hantzsch data, with a slope close to unity ( $b=0.90, a=0.63$ ). Similarly, a regression line with no significant deviation from the one-to-one line was found for FTIR versus PSI. As a smaller number of data points was available, the degree of correlation is somewhat lower (Fig. 3k). The correlation coefficient between FTIR and IFU1 data for the time span until 28 July is lower $(r=0.65)$. There is a significant deviation from the 1:1 line $(b=0.79)$, with IFU1 showing the larger values. After 28 July IFU1 measures significantly lower concentrations than the FTIR. A good agreement was found between FTIR and IFU2 (values after 26 July) with a slope of $b=0.97$ $(r=0.90)$, whereas the employment of the complete data set 
Table 2. Results of the orthogonal regression analysis (York, 1966) between the continuous instruments (see also Fig. 3). $\left[\mathrm{CH}_{2} \mathrm{O}\right]_{\mathrm{y}}=a+b\left[\mathrm{CH}_{2} \mathrm{O}\right]_{\mathrm{x}}$, where $\mathrm{y}$ and $\mathrm{x}$ are the corresponding instruments, and $\mathrm{a}$ and $\mathrm{b}$ are the intercept and slope of the regression line, respectively with $95 \%$ confidence intervals. $N$ is the number of data points included in the regression, and $r$ is Pearson's correlation coefficient. The first column indicates the corresponding plot in Fig. 3 (for some regressions no plot is shown).

\begin{tabular}{lllrlll}
\hline Fig. & y & x & $a$ [ppbv] & $b$ & $r$ & $N$ \\
\hline a) & IFU 1* & BUW & $1.02 \pm 0.17$ & $1.22 \pm 0.05$ & 0.96 & 142 \\
b) & IFU 1 & PSI & $0.72 \pm 0.40$ & $1.11 \pm 0.09$ & 0.93 & 83 \\
c) & PSI & BUW & $0.46 \pm 0.12$ & $1.04 \pm 0.03$ & 0.99 & 128 \\
d) & IFU 2* & BUW & $0.81 \pm 0.15$ & $0.95 \pm 0.04$ & 0.97 & 112 \\
-) & IFU 2 & PSI & $1.49 \pm 0.65$ & $0.96 \pm 0.16$ & 0.58 & 100 \\
e) & IFU 2* & IFU 1 & $0.64 \pm 0.22$ & $0.64 \pm 0.06$ & 0.94 & 62 \\
f) & IFU 3 & BUW & $0.55 \pm 0.21$ & $0.98 \pm 0.07$ & 0.88 & 155 \\
g) & IFU 3 & PSI & $-0.08 \pm 0.21$ & $1.03 \pm 0.06$ & 0.98 & 55 \\
h) & IFU 1* & IFU 3 & $0.28 \pm 0.39$ & $1.20 \pm 0.12$ & 0.85 & 103 \\
i) & IFU 3 & IFU 2* & $-0.42 \pm 0.47$ & $1.07 \pm 0.13$ & 0.78 & 101 \\
j) & FTIR & BUW & $0.63 \pm 0.40$ & $0.90 \pm 0.09$ & 0.82 & 105 \\
k) & FTIR & PSI & $0.25 \pm 0.74$ & $0.88 \pm 0.14$ & 0.72 & 77 \\
1) & FTIR & IFU 1* & $-0.19 \pm 0.73$ & $0.79 \pm 0.14$ & 0.65 & 73 \\
-) & FTIR & IFU 2* & $-0.22 \pm 0.71$ & $0.97 \pm 0.15$ & 0.90 & 35 \\
m) & FTIR & IFU 3 & $0.60 \pm 0.62$ & $0.77 \pm 0.16$ & 0.47 & 54 \\
n) & DOAS & BUW & $0.39 \pm 0.27$ & $0.96 \pm 0.08$ & 0.90 & 132 \\
o) & DOAS & PSI & $-0.15 \pm 0.56$ & $0.92 \pm 0.15$ & 0.81 & 57 \\
p) & DOAS & IFU 1* & $-0.93 \pm 0.84$ & $0.90 \pm 0.18$ & 0.71 & 79 \\
-) & DOAS & IFU 2* & $-0.07 \pm 0.49$ & $0.93 \pm 0.11$ & 0.93 & 69 \\
q) & DOAS & IFU 3 & $-0.02 \pm 0.48$ & $0.98 \pm 0.15$ & 0.70 & 100 \\
r) & DOAS & FTIR & $0.40 \pm 0.39$ & $0.92 \pm 0.09$ & 0.81 & 90 \\
\hline & & & & & & \\
\hline
\end{tabular}

* Note that the regression results given for the IFU2 instrument were calculated omitting the data of 25 and 26 July, and the regression results for IFU1 exclude data after 28 July, 09:15 CEST.

shows strong scattering. No coherence is recognizable between FTIR and IFU3, where only 54 mutual data points are available. The observed concentration range is very small here.

A large amount of mutual data points was obtained for the pair DOAS and BUW, where a good correlation $(r=0.90)$ is found. The slope of the regression line is not significantly different from unity $(b=0.96)$. There was also good agreement between DOAS and PSI $(r=0.81, b=0.92)$. The $1: 1$ line is enclosed within the $95 \%$ confidence interval of the regression slope and there is no significant offset. IFU1 first measured considerably higher values than the DOAS ( $b=0.90, a=-0.93)$. The result for the second period is shown by the second regression line in Fig. 3p. For values after 26 July, the agreement between DOAS and IFU2 is good ( $r=0.93, b=0.93$, no significant offset). However, including the complete IFU2 data set reveals less agreement. The regression between DOAS and IFU3 displays a slope not significantly different from unity and no significant offset.
Table 3. Linear orthogonal regressions (York, 1966) for the correlations between DNPH and the continuous methods (see also Fig. 4). The definition of parameters is specified in Table 2 .

\begin{tabular}{lllrlll}
\hline Fig. & $\mathrm{y}$ & $\mathrm{x}$ & $a$ [ppbv] & $b$ & $r$ & $N$ \\
\hline a) & DNPH & BUW & $0.92 \pm 0.45$ & $0.76 \pm 0.12$ & 0.90 & 30 \\
b) & DNPH & PSI & $0.37 \pm 0.75$ & $0.76 \pm 0.16$ & 0.86 & 26 \\
c) & DNPH & FTIR & $0.76 \pm 0.87$ & $0.74 \pm 0.20$ & 0.66 & 31 \\
d) & DNPH & IFU 1 & $0.51 \pm 1.08$ & $0.64 \pm 0.23$ & 0.40 & 27 \\
-) & DNPH & IFU 2* & $-0.23 \pm 1.71$ & $0.97 \pm 0.48$ & 0.59 & 13 \\
e) & DNPH & IFU 3 & $0.28 \pm 0.88$ & $0.83 \pm 0.24$ & 0.74 & 23 \\
f) & DNPH & DOAS & $0.77 \pm 0.81$ & $0.80 \pm 0.23$ & 0.75 & 23 \\
\hline
\end{tabular}

\subsubsection{Agreement among spectroscopic techniques (r)}

The FTIR measured predominantly during daylight hours, whereas the DOAS system was generally also operated at night (Fig. 2b). Altogether, there are 90 mutual points between the two White systems ( 30 min averages) during the intercomparison week. The correlation is moderate with $r=0.81$. At the $95 \%$ confidence level the regression slope $(b=0.92)$ is not significantly different from unity.

Both instruments detect the average concentrations along the respective light paths. During the intensive lorry experiment, the lorries were located upwind of the air volume surveyed by both White systems. A comparison was performed using $10 \mathrm{~min}$ averages, due to the temporal limitation of the experiment to two events of $30 \mathrm{~min}$ each. Maximum values around $19 \mathrm{ppbv}$ (10 min average) were measured by both instruments during the lorry experiment and a correlation of $r=0.89$ and a slope of $b=1.03$ were found, thus nearly yielding a one-to-one correspondence. The dashed line in Fig. 3r is the regression line to the ten minute data including the lorry experiment (grey markers).

\subsubsection{Agreement between continuous instruments and DNPH}

The DNPH samples were taken every two hours during daytime. Therefore two hour averages of the continuous instruments were compared to the integrated results obtained from the cartridges. As mentioned before, the data containing the lorry plumes was omitted in the calculations. The results are presented in scatter plots in Fig. 4a-f. The statistical parameters are summarised in Table 3. For all cases, the regression slopes are below unity, however for IFU2, IFU3 and DOAS unity is included within the $95 \%$ confidence interval. The regression analysis for DNPH versus Hantzsch BUW and PSI revealed slopes of $b=0.76$ and correlation coefficients of around $r=0.90$. The instruments IFU1, IFU2, IFU3 attained correlation coefficients of $r=0.40,0.59,0.74$ (note the different measurement intervals; IFU2 values after 26 July) with systematically higher values for IFU1 than 

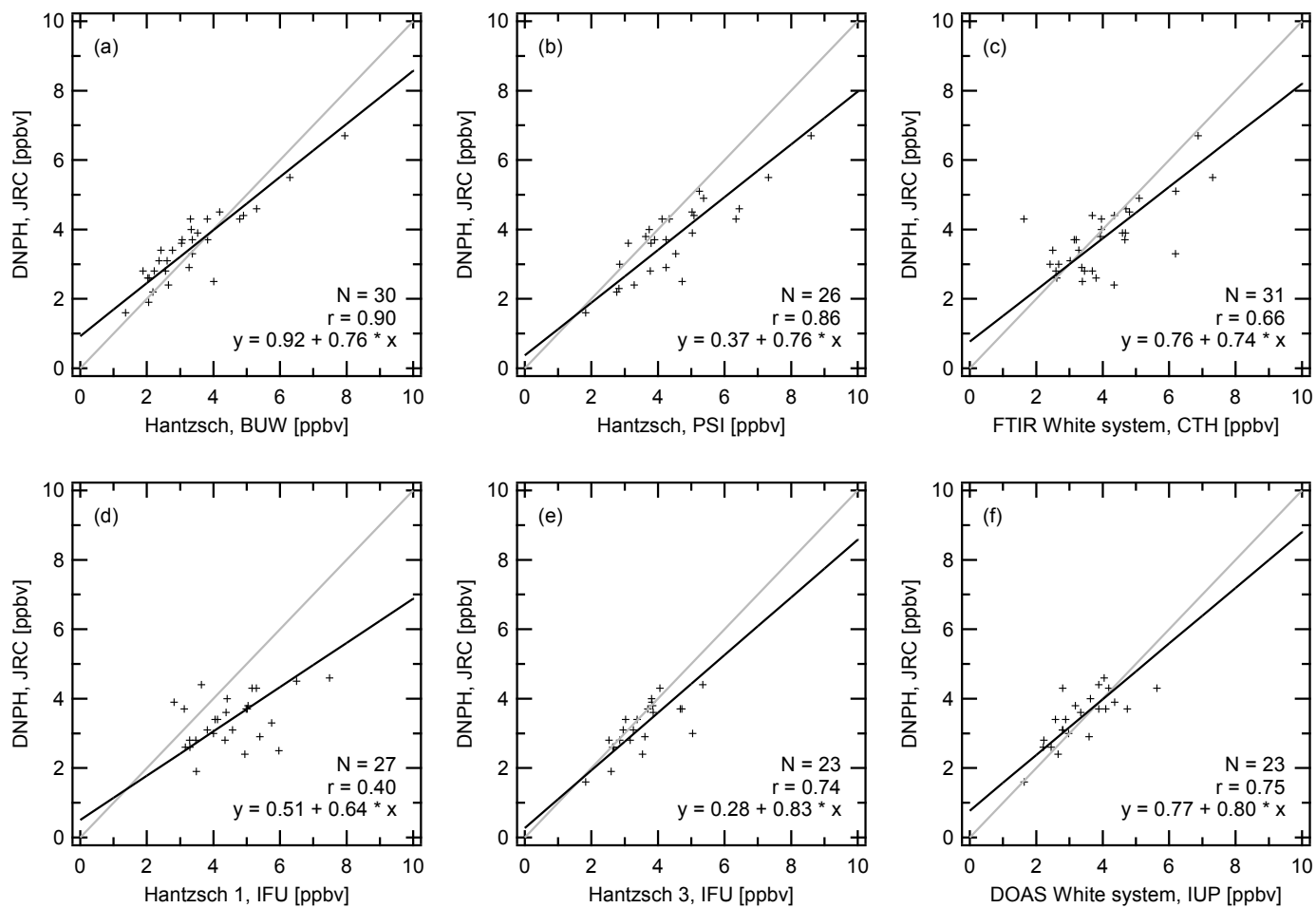

Fig. 4. Regressions of the DNPH cartridge results from the intercomparison week plotted versus those from continuous techniques for concordant two hour time spans. The solid black line drawn through the data is the orthogonal least squares fit to the data (York, 1966). The grey line represents the one to one correspondence.

for the DNPH. The slopes of IFU1, IFU2, IFU3 are $b=0.64$, 0.97, 0.83. Plotting the DNPH data versus the FTIR data also reveals a regression slope lower than unity $(b=0.74)$ and an intercept not significantly different from zero (correlation coefficient $r=0.66$ ).

The mixing ratios measured by DNPH, Hantzsch, DOAS, and FTIR techniques correspond moderately well to each other on the two hour time scale. However, short term variations cannot be resolved. In summary, the DNPH results are slightly lower than those measured by the continuous instruments for up to 30 common data points in the concentration range from 1 to $8 \mathrm{ppbv}$.

\subsection{Fractional differences}

The agreement between measurements of the continuous instruments and a reference instrument is summarised in histograms of the fractional differences $\delta=\left(\left[\mathrm{CH}_{2} \mathrm{O}\right]_{\text {instr }}{ }^{-}\right.$ $\left.\left[\mathrm{CH}_{2} \mathrm{O}\right]_{\text {ref }}\right) /\left[\mathrm{CH}_{2} \mathrm{O}\right]_{\text {ref. }}$. For the comparison among the continuous instruments, the BUW Hantzsch was chosen as a reference because it was almost continuously operating over the entire intercomparison period. The results are depicted in Fig. 5a for the overall data sets. Figure 5b shows the resulting fractional differences for the two-hour integrated measurements of all instruments, using the DNPH data as reference.
The plots show the histograms of the data (shaded bars) and fitted Gaussian functions (black curve). The respective statistical information is given in the legend of each plot. The fact that the average, median, and mode (i.e., the most probable fractional difference) of the PSI, IFU1, and IFU3 distributions are similarly positioned suggests symmetry in the distributions and therefore mostly random differences. The PSI histogram has a narrow distribution with a standard deviation of $\sigma=0.12$. The DOAS, FTIR, IFU1, IFU2, and IFU3 histograms show $\sigma$ of $0.27,0.27,0.21,0.66$ and 0.18 , respectively. The IFU2 histogram has a slightly skew distribution which is due to the erroneous results from 25 and 26 July. After eliminating those outliers, the IFU2 histogram shows an almost symmetrical $\delta$-distribution. In this case, the average, median, and mode are nearly collocated (average $=0.23$, median $=0.19$, mode $=0.21$ ) and the standard deviation is decreased to 0.24 . The distributions for the spectroscopic techniques DOAS and FTIR are wider than those for most of the Hantzsch instruments. Most instruments show a positive bias with respect to the reference BUW Hantzsch instrument. The relative difference between the DOAS and the BUW Hantzsch is $+9 \%$. On average, 3\% lower values were found for the FTIR than for the BUW. The PSI, IFU1, IFU2 and IFU3 values were approximately 20, 58, 21 and $23 \%$ higher than the BUW results, respectively. After the instrumental modification of IFU1, the results were $19 \%$ 
(a)
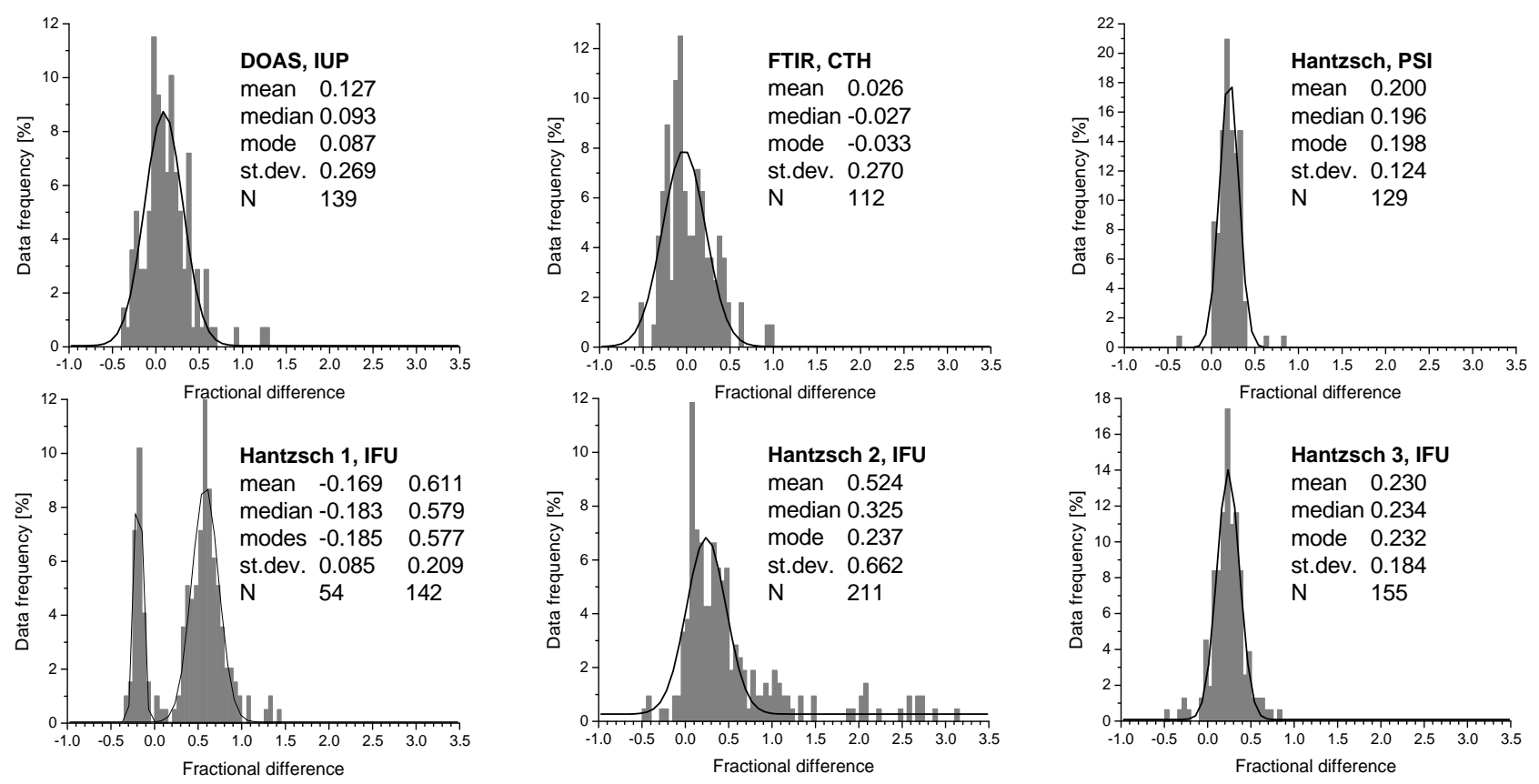

Fig. 5. Fractional difference histograms for each of the formaldehyde instruments calculated relative to a reference instrument. For the comparison of (a) the continuously measuring techniques, the reference instrument is the BUW Hantzsch monitor, in (b) the reference instrument is the DNPH sampler. Each panel shows the frequency for the data falling into 0.05 fractional difference bins (normalised to the number of coincident data pairs). The legends show the statistics for the complete data sets.

smaller than those from BUW. In order to verify the relative differences between the results of the seven instruments, fractional differences were also calculated using DOAS as a reference (Table 4, lower row). The previous result was confirmed, with the Hantzsch measurements (except IFU1) being within the $\pm 11 \%$ range of the DOAS. DOAS and FTIR agree within $5 \%$. This is also consistent with the uncertainty of the used cross-sections. The relative deviations obtained with the fractional differences are in line with the uncertainties expected from Table 2.

As the sample size is small for the fractional differences relative to DNPH $(\mathrm{N}=23-31$, see Table 3$)$, it was refrained from fitting Gaussians to the histograms (Fig. 5b). The distributions for DOAS, FTIR, PSI and IFU3 are almost symmetrical. The histogram for IFU2 is less symmetrical because of several higher fractional differences caused by the instrumental problems during the first days. If these days are omitted, only two days of common data points are remaining. The data sets of DOAS, FTIR, PSI, IFU3, and BUW agreed with the DNPH results within $\sim 15 \%$. For IFU1 and IFU2, the differences were larger. Mean and median coincide only in a few cases. Due to the small sample sizes of only 20 30 data points, the statistical information should be regarded carefully in this part of the study.

\subsection{Comparison of Hantzsch calibration standards}

Formaldehyde solutions with a known concentration are required in the calibration of the Hantzsch instruments. These solutions are produced by diluting a commercially available $37 \% \mathrm{CH}_{2} \mathrm{O}$-solution to a stock-solution of about $10^{-1}$ to $10^{-2} \mathrm{~mol} / \mathrm{l}$, which is titrated regularly and is then further diluted to about $10^{-6} \mathrm{~mol} / \mathrm{l}$ for calibration (see also Aero Laser AL4001 HCHO analyser manual). Formaldehyde solutions with high concentrations contain a significant fraction of para-formaldehyde which interferes with the titration. Although the para-formaldehyde concentration is negligible in diluted solutions, a waiting time of at least $24 \mathrm{~h}$ between dilution and titration is recommended to ensure the conversion of all para-formaldehyde. These diluted solutions are stable over years, with less than 0.2 percent deviation within one year.

The IFU $0.01 \mathrm{~mol} / \mathrm{l}$ and PSI $0.05 \mathrm{~mol} / 1$ diluted standards were both shown to be stable within less than a percent deviation over several years. The field standards were taken from these working standards, stored in cooled boxes and further diluted to concentrations of $\sim 10^{-6} \mathrm{~mol} / \mathrm{l}$ in the field for calibration. At this level of dilution, the solution is no longer stable for more than one hour even when stored in a refrigerator. 
(b)
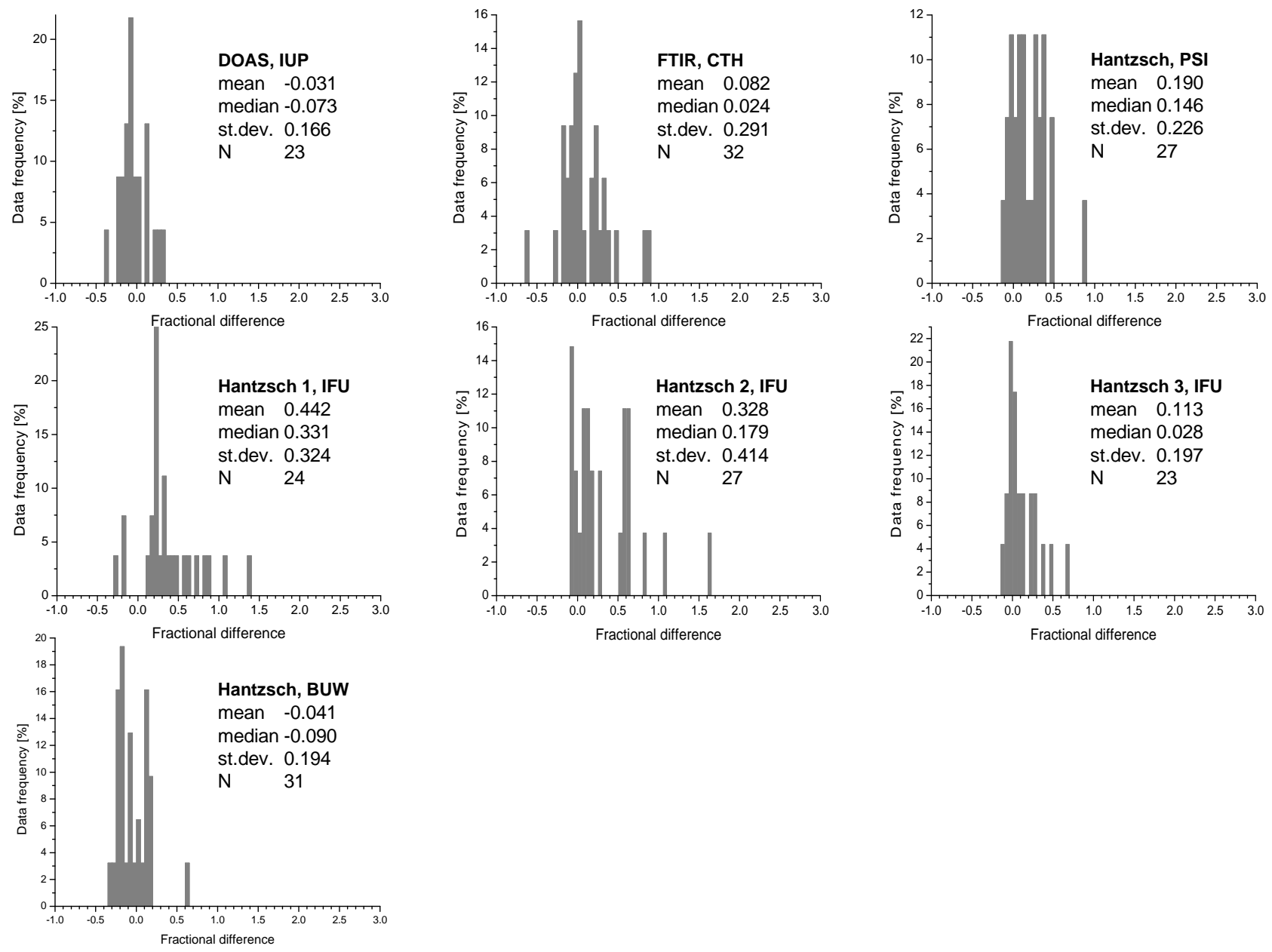

Fig. 5. Continued.

Table 4. Relative differences of the measurement results determined with reference to BUW Hantzsch (see also Fig. 5a) and to DOAS, respectively.

\begin{tabular}{llllllll}
\hline & DOAS & FTIR & PSI & IFU 1 & IFU 2 & IFU 3 & BUW \\
\hline Relative to BUW Hantzsch & $+8.8 \%$ & $-3.3 \%$ & $+19.8 \%$ & $+57.7 \%$ & $+21.0 \%$ & $+23.2 \%$ & - \\
& & & & $-18.5 \%$ & & & \\
Relative to DOAS White cell & - & $-5.1 \%$ & $+11.1 \%$ & $+41.3 \%$ & $+10.6 \%$ & $+7.2 \%$ & $-10.3 \%$ \\
& & & & -19.2 & & & \\
\hline
\end{tabular}

The liquid formaldehyde standards, which were used by IFU, PSI and BUW for the calibration of their Hantzsch instruments, were independently prepared by each group.

At the beginning of the campaign (on 24 July), the standard solutions (levels about $10^{-6} \mathrm{~mol} / \mathrm{l}$ ) of the three groups were compared using one of the IFU instruments (SN28, in this study called 'IFU3'). Each group prepared a solution of $\sim 10^{-6} \mathrm{~mol} / \mathrm{l}$ from the individual standards. The standards by BUW and PSI agreed within 5\% (PSI/BUW=1.05). However, the results indicated a $\sim+30 \%$ deviation of the calibration standards of IFU when compared to the other groups. A $6 \%$ difference between the standard solutions of BUW and PSI was found on the same day using the PSI instrument (PSI/BUW=1.06).

After the first discrepancies were observed in the data, the working standards of IFU and PSI were again analysed in 
Table 5. Recipes for the ingredients of the Hantzsch solution as used by the three groups.

\begin{tabular}{llll}
\hline & Kelly and Fortune & IFU (Aero Laser) & PSI \\
\hline Ammonium acetate & $462 \mathrm{~g} / 1$ & $154 \mathrm{~g} / 1$ & $154 \mathrm{~g} / 1$ \\
Acetic acid & $10 \mathrm{ml} / 1$ & $5 \mathrm{ml} / 1$ & $5 \mathrm{ml} / 1$ \\
Acetylacetone & $1 \mathrm{~m} / 1$ & $4 \mathrm{ml} / 1$ & $4 \mathrm{ml} / 1$ \\
\hline
\end{tabular}

the PSI- and IFU-laboratories. The analyses again yielded a $30 \%$ higher concentration for the IFU standard than for the PSI standard, although both stated to be $1.0 \times 10^{-2}$ molar according to the original titrations. Hence, there was a $30 \%$ difference between the titration methods used by IFU and PSI, even though both from dilution and titration they were expected to agree within a few percent.

Different titration methods are available and are commonly used among the different laboratories for this concentration range. Unfortunately, they do not totally agree with one another. To date it was impossible to solve the apparent differences of up to $30 \%$.

The difference of 30\% between the IFU standard and the calibration standards of other groups was obtained repeatedly. It could explain the found disagreement between IFU instruments and the BUW instrument, IFU2 and IFU3 values being $23 \%$ higher than BUW data. About $6 \%$ of the discrepancy between PSI and BUW can be explained by the different standards. The remaining 10-15\% difference is undetermined. The IFU1 instrument deviates significantly from the results of the majority of the Hantzsch instruments. A new, larger internal zero trap was installed in this instrument after the first week of the intercomparison following an instrument malfunction (flooding of the zero trap). The quality of the zero baseline is critical in this technique and the differences of this instrument when compared to the other ones are most probably due to zero baseline problems.

Another process carried out differently by the three groups was the preparation of the Hantzsch solution. The used recipes differ in the concentrations of the chemicals (see overview in Table 5), and minor differences exist in the production technique of the solution, i.e. if the solution was degassed, whether acetyl acetone was distilled, etc.

PSI and IFU used a modified recipe for the Hantzsch solution, compared to the original recipe from Kelly and Fortune (1994) used by BUW (less ammonium acetate but more acetylacetone). Aero Laser now recommends the new recipe for concentration ranges up to $30 \mathrm{ppbv}$.

\subsection{Comparison of UV absorption cross-sections}

The spectroscopic methods FTIR and DOAS have an independent absolute calibration, based on absorption cross-

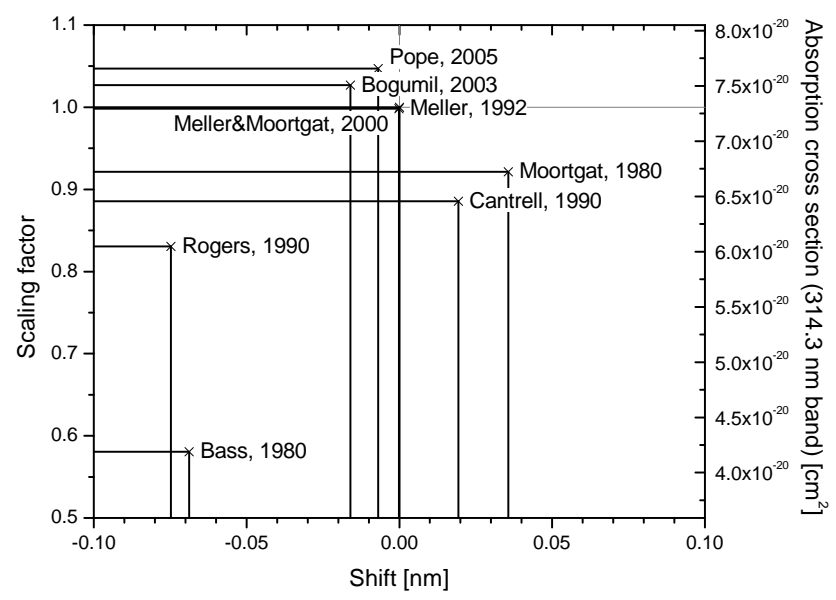

Fig. 6. Overview on the differences in magnitude and wavelength calibration of the available highly-resolved absorption crosssections of formaldehyde with respect to the spectrum by Meller and Moortgat (2000).

section data of formaldehyde (and other trace gases absorbing in the observed spectral range) measured in the laboratory. The absorption structure is a unique property of each compound. The accuracy of a DOAS measurement is influenced mostly by the accuracy of the used cross-section.

The DOAS method requires the knowledge of accurate absolute absorption cross-sections of the investigated species. A variety of high-resolution absorption cross-sections of formaldehyde in the UV spectral range are available. Since 2002 the International Union of Pure and Applied Chemistry (IUPAC) Subcommittee on Gas Kinetic Data Evaluation for Atmospheric Chemistry (Atkinson et al., 2002) recommends the use of the Meller and Moortgat (2000) data over the entire spectral range, yet the measured crosssections are reported $5-10 \%$ higher than the values previously recommended. However, the NASA evaluation of 2003 (Sander et al., 2003), recommends the absorption crosssection by Cantrell et al. (1990), which only covers a limited wavelength range $(\lambda=300-375.5 \mathrm{~nm})$.

Other cross-sections reported in literature were not recommended due to various issues. Problems with the strong absorption bands between 320 and $350 \mathrm{~nm}$ are reported for the cross-section by Bass et al. (1980). Rogers (1990) reportedly contains discrepancies at wavelengths shorter than $280 \mathrm{~nm}$ (Meller and Moortgat, 2000). A very highly resolved cross-section including two absorption bands between 313 and $320 \mathrm{~nm}$ was recently published by Pope et al. (2005).

The seven available $\mathrm{CH}_{2} \mathrm{O}$ absorption cross-sections are compared in the spectral range $300-360 \mathrm{~nm}$, with the exception of the cross-section by Pope et al. (2005), for which a smaller range was used. Since the spectra were recorded at different spectral resolutions $R_{i}$, they had to be adapted to a common spectral resolution of $0.5 \mathrm{~nm}$ FWHM. This was accomplished by convolution with Gaussian functions 
Table 6. Overview of previous formaldehyde intercomparisons including this study. Techniques which are also included in the present study are marked bold.

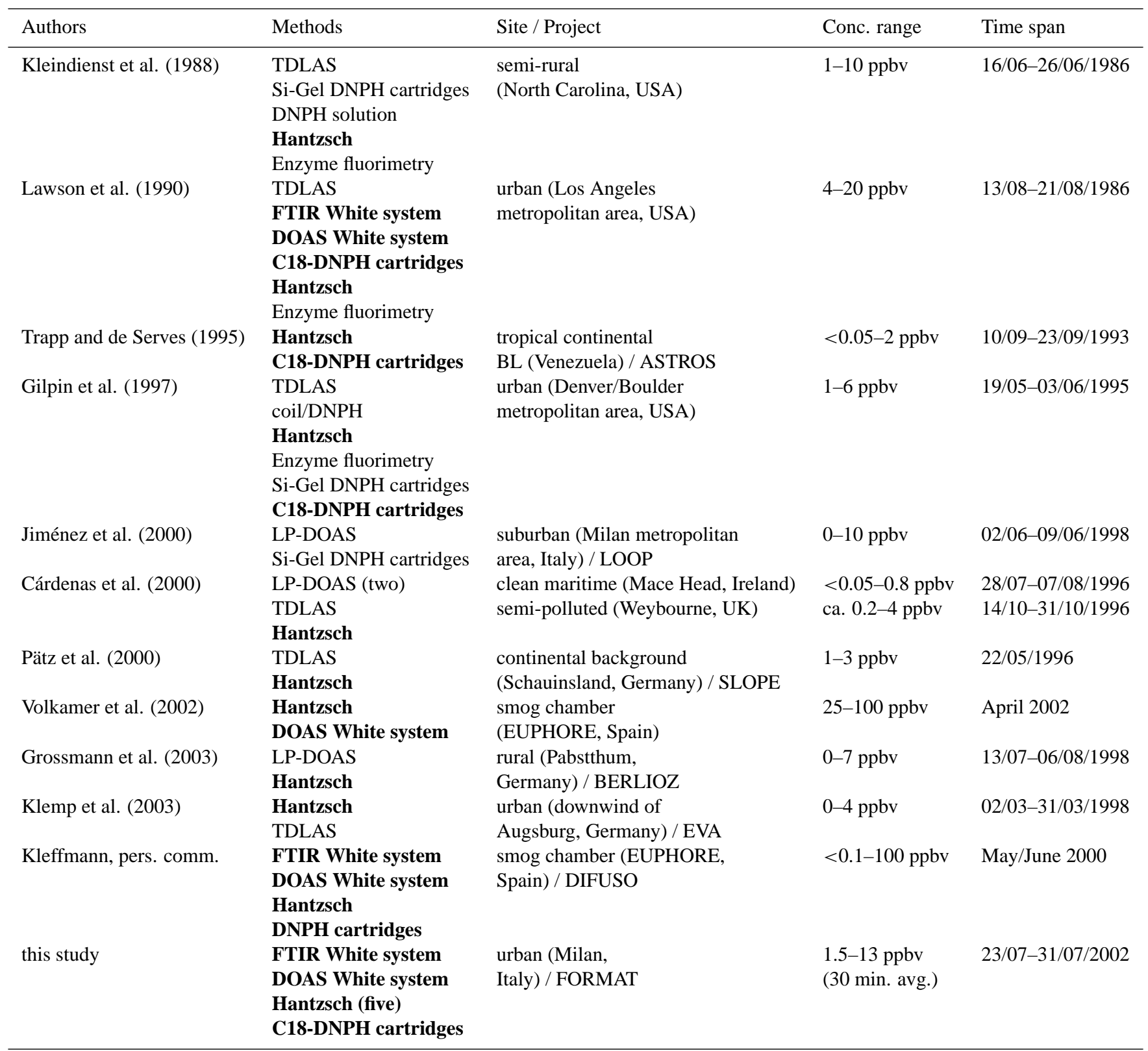

of FWHM $G_{i}\left(G_{i}^{2}=(0.5 \mathrm{~nm})^{2}-R_{i}^{2}\right)$. For comparison of the cross-sections a non-linear least-squares fit with five fitting parameters was employed: A quadratic polynomial (three parameters) accounting for small baseline differences, a scaling coefficient accounting for differences in the absolute magnitude of the cross-sections (one parameter), and a linear wavelength shift coefficient (one parameter) accounting for differences in the wavelength calibration. During non-linear fitting, a linear shift and a polynomial high pass filter were employed to minimise the influence of wavelength shifts and of baseline drifts and stray light. With this method the crosssection by Meller and Moortgat (2000) was fitted to the other cross-sections. The observed differences in magnitude and wavelength shifts relative to the cross-section by Meller and Moortgat (2000) are summarised in Fig. 6.

The recommended $\mathrm{CH}_{2} \mathrm{O}$ cross-sections (Meller and Moortgat, 2000; Cantrell et al., 1990, see above) differ by $11.4 \%$ in the spectral range between 300 and $360 \mathrm{~nm}$. 
There is a small wavelength shift of about $0.02 \mathrm{~nm}$ between both cross-sections. The differences in the absorption crosssections imply a potential $11 \%$ difference in the concentrations determined by DOAS depending on the cross-section used by the particular authors. In previous comparisons, the cross-section employed in the DOAS retrieval process was often not specified by the authors.

\section{Summary and conclusions}

An intercomparison of most in-situ measurement techniques currently used for the detection of atmospheric formaldehyde, including the Hantzsch technique, FTIR, DOAS, and a DNPH-sampler, is presented. Five Hantzsch instruments of nearly identical design, operated by three laboratories, sampled from a common inlet line. The use of White-type multireflection systems for the spectroscopic DOAS and FTIR techniques ensured probing of nearly the same air volume by all eight instruments. The measurement conditions and equipment used during this and previous comparison studies are summarised in Table 6 .

$\mathrm{CH}_{2} \mathrm{O}$ mixing ratios varied between 1 and 13 ppbv. The Hantzsch results showed a rather large variation. After elimination of some apparently unreliable measurement sequences of two instruments, the results varied within $\pm 11 \%$ among each other, except for one instrument, which systematically gave much higher values. The agreement of the two optical methods was within $5 \%$, which is within the uncertainties of the UV and IR absorption cross-sections (both $5 \%)$. Hantzsch and spectroscopic techniques agreed within $15 \%$. DNPH measurements were generally lower than the continuous techniques by up to $25 \%$. Observed discrepancies among the Hantzsch instruments can partly be attributed to the different calibration standards used by the different groups. The apparent differences in the titration methods for the $10^{-2}$ molar standard solution could not be solved finally within this project and could account for absolute differences of about $30 \%$. The Hantzsch instruments BUW and PSI show an excellent correlation but an offset of $20 \%$ in the results. The reason for this could not be ascertained. Such an effect could occur when the zeroing is insufficient due to a malfunctioning formaldehyde scrubber or too short a zeroing time. The found differences in magnitude of the compared UV absorption cross-sections imply possible differences of up to $11 \%$ in the concentrations determined by DOAS, depending on the employed cross-section.

It is usually difficult to compare DOAS or FTIR long path measurements with point measurements since the probed air masses often differ from one another. In urban areas, this is mainly caused by primary emissions on a local scale and fast secondary formation as a consequence of the oxidation of anthropogenically emitted VOCs. In rural areas, especially close to forests, secondary formation due to the oxidation of biogenically emitted VOCs, plays an important role. The measurement setup used during this intercomparison, sampling a uniform air mass by the folding of the light beams in the White cells, was therefore most favourable to measure under homogeneous conditions with the employed techniques.

The Hantzsch results agree generally well with the results of the spectroscopic techniques. With three independent techniques (DOAS, FTIR, and Hantzsch) applying completely different ways of determining the formaldehyde concentration, results within $15 \%$ were obtained. Previously observed significant differences in mixing ratios obtained by Hantzsch monitors and the DOAS technique (e.g. BERLIOZ campaign, see Grossmann et al., 2003) could not be observed in this study. No systematic difference between DOAS and Hantzsch was found under the conditions present during the comparison measurements. It is assumed that the improvement is due to the employment of multi-reflection setups in the spectroscopic techniques which ensured that all instruments sampled essentially the same air volume.

Previously reported differences between DOAS and Hantzsch techniques seem to be larger than the uncertainties in $\mathrm{CH}_{2} \mathrm{O}$ measurements as characterised in this study, and thus may have been caused by spatial (vertical) gradients of $\mathrm{CH}_{2} \mathrm{O}$ concentrations.

Acknowledgements. The authors would like to thank the staff of the Italian Red Cross section at the airport in Bresso (Milano) for their great hospitality. This work is part of the FORMAT project, a study supported by the EU to improve scientific understanding of the role of formaldehyde in photochemistry (project FORMAT, http://www.nilu.no/format/, grant EVK2-CT-2001-00120). R. Volkamer is grateful for support from M. and L. Molina and a Dreyfus Postdoctoral Fellowship.

Edited by: G. O. Braathen

\section{References}

Alicke, B., Stutz, J., and Platt, U.: Impact of nitrous acid photolysis on the total hydroxyl radical budget during the Limitation of Oxidant Production/Pianura Padana Produzione di Ozono study in Milan, J. Geophys. Res., 107(D22), 8196, doi:10.1029/2000JD000075, 2002.

Atkinson, R., Baulch, D. L., Cox, R. A., et al.: http://www.iupac-kinetic.ch.cam.ac.uk/datasheets/photol/ P1_HCHO+hv.pdf, 2002.

Bass, A. M., Glasgow, L. C., Miller, C., Jesson, J. P., and Filkin, D. L.: Temperature dependent absorption cross sections for formaldehyde $\left(\mathrm{CH}_{2} \mathrm{O}\right)$ : The effect of formaldehyde on stratospheric chlorine chemistry, Planet. Space Sci., 28, 675-679, 1980.

Bogumil, K., Orphal, J., Homann, T., Voigt, S., Spietz, P., Fleischmann, O. C., Vogel, A., Hartmann, M., Kromminga, H., Bovensmann, H., Frerick, J., and Burrows, J. P.: Measurements of molecular absorption spectra with the SCIAMACHY preflight model: instrument characterization and reference data for 
atmospheric remote-sensing in the $230-2380 \mathrm{~nm}$ region, J. Photochem. Photobiol. A, 157, 167-184, 2003.

Calogirou, A., Larsen, B. R., and Kotzias, D.: Gas-phase terpene oxidation products - a review, Atmos. Environ., 33, 1423-1439, 1999.

Cantrell, C. A., Davidson, J. A., McDaniel, A. H., Shetter, R. E., and Calvert, J. G.: Temperature-dependent formaldehyde cross sections in the near-ultraviolet spectral region, J. Phys. Chem., 94, 3902-3908, 1990.

Cárdenas, L. M., Brassington, D. J., Allan, B. J., Coe, H., Alicke, B., Platt, U., Wilson, K. M., Plane, J. M., and Penkett, S. A.: Intercomparison of formaldehyde measurements in clean and polluted atmospheres, J. Atmos. Chem., 37, 53-80, 2000.

Carlier, P., Hannachi, H., and Mouvier, G.: The Chemistry of Carbonyl Compounds in the Atmosphere - a review, Atmos. Environ., 20, 2079-2099, 1986.

Duane, M., Poma, B., Rembges, D., Astorga, C., and Larsen, B. R.: Isoprene and its degradation products as strong ozone precursors in Insubria, Northern Italy, Atmos. Environ., 36, 3867-3879, 2002.

Gilpin, T., Apel, E., Fried, A., Wert, B., Calvert, J., Genfa, Z., Dasgupta, P., Harder, J. W., Heikes, B., Hopkins, B., Westberg, H., Kleindienst, T., Lee, Y. N., Zhou, X., Lonneman, W., and Sewell, S.: Intercomparison of six ambient $\left[\mathrm{CH}_{2} \mathrm{O}\right]$ measurement techniques, J. Geophys. Res., 102, 21 161-21 188, 1997.

Gomer, T., Brauers, T., Heintz, F., Stutz, J., and Platt, U.: MFC User Manual, Version 1.98, Institut für Umweltphysik, Universität Heidelberg, 1995.

Griffith, D. W. T.: Synthetic calibration and quantitative analysis of gas-phase infrared spectra, Appl. Spectrosc., 50, 59-70, 1996.

Grosjean, D.: Ambient Levels of Formaldehyde, Acetaldehyde, and Formic Acid in Southern California: Results of a One-Year BaseLine Study, Environ. Sci. Technol., 25, 710-715, 1991.

Grossmann, D., Moortgat, G. K., Kibler, M., Schlomski, S., Bächmann, K., Alicke, B., Geyer, A., Platt, U., Hammer, M. U., Vogel, B., Mihelcic, D., Hofzumahaus, A., Holland, F., and Volz-Thomas, A.: Hydrogen peroxide, organic peroxides, carbonyl compounds, and organic acids measured at Pabstthum during BERLIOZ, J. Geophys. Res., 108(D4), 8250, doi:10.1029/2001JD001096, 2003.

Heikes, B. G.: Formaldehyde and Hydroperoxides at Mauna Loa Observatory, J. Geophys. Res., 97, 18 001-18 013, 1992.

Jiménez, R., Martilli, A., Balin, I., v. d. Bergh, H., Calpini, B., Larsen, B. R., Favaro, G., and Kita, D.: Measurement of Formaldehyde (HCHO) by DOAS: Intercomparison to DNPH Measurements and Interpretation from Eulerian Model Calculations, Proceedings of the 93rd Annual Conference \& Exhibition, Air \& Waste Management Association, Paper \#829, Salt Lake City, Utah, June 18-22, 2000.

Junkermann, W. and Stockwell, W. R.: On the budget of photooxidants in the marine boundary layer of the tropical South Atlantic, J. Geophys. Res., 104(D7), 8039-8046, 1999.

Kelly, T. J. and Fortune, C. R.: Continuous monitoring of gaseous formaldehyde using an improved fluorescence approach, Int. J. Environ. Anal. Chem., 54, 249-263, 1994.

Kesselmeier, J., Bode, K., Hofmann, U., Müller, H., Schäfer, L., Wolf, A., Ciccioli, P., Brancaleoni, E., Cecinato, A., Frattoni, M., Foster, P., Ferrari, C., Jacob, V., Fugit, J. L., Dutaur, L., Simon, V., and Torres, L.: Emission of short chained organic acids, alde- hydes and monoterpenes from Quercus Ilex L. and Pinus Pinea L. in relation to physiological activities, carbon budget and emission algorithms, Atmos. Environ., 31, SI, 119-133, 1997.

Kleindienst, T. E., Shepson, P. B., Nero, C. M., Arnts, R. R., Tejada, S. B., Mackay, G. I., Mayne, L. K., Schiff, H. I., Lind, J. A., Kok, G. L., Lazrus, A. L., Dasgupta, P. K., and Dong, S.: An Intercomparison of Formaldehyde Measurement Techniques at ambient Concentration, Atmos. Environ., 22, 1931-1939, 1988.

Klemp, D., Mannschreck, K., and Mittermaier, B.: Comparison of two different HCHO Measurement Techniques: TDLAS and a commercial Hantzsch Monitor - Results from Long term Measurements in a City Plume during the EVA Experiment, in: Emissions of Air Pollutants - Measurements, Calculations and Uncertainties, edited by: Friedrich, R. and Reis, S., Springer Verlag, 2003.

Lawson, D. R., Biermann, H. W., Tuazon, E. C., Winer, A. M., Mackay, G. I., Schiff, H. I., Kok, G. L., Dasgupta, P. K., and Fung, K.: Formaldehyde measurement methods evaluation and ambient concentrations during the Carbonaceous Species Methods Comparison Study, Aerosol Sci. Technol., 12, 64-76, 1990.

Lee, Y. N., Zhou, X., Kleinman, L. I., Nunnermacker, L. J., Springston, S. R., Daum, P. H., Newman, L., Keigley, W. G., Holdren, M. W., Spicer, C. W., Young, V., Fu, B., Parrish, D. D., Holloway, J., Williams, J., Roberts, J. M., Ryerson, T. B., and Fehsenfeld, F. C.: Atmospheric chemistry and distribution of formaldehyde and several multioxygenated carbonyl compounds during the 1995 Nashville/Middle Tennessee Ozone Study, J. Geophys. Res., 103(D17), 22 449-22 462, 1998.

Lowe, D. C. and Schmidt, U.: Formaldehyde (HCHO) Measurements in the Nonurban Atmosphere, J. Geophys. Res., 88(C15), 10 844-10 858, 1983.

Meller, R. and Moortgat, G. K.: Temperature dependence of the absorption cross sections of formaldehyde between 223 and $323 \mathrm{~K}$ in the wavelength range $225-375 \mathrm{~nm}$, J. Geophys. Res., 201(D6), 7089-7101, 2000.

Nash, T.: The colorimetric estimation of formaldehyde by means of the Hantzsch reaction, Biochem. J., 55, 416-421, 1953.

National Research Council (NRC): Formaldehyde - An Assessment of its Health Effects, National Academy of Sciences, Washington, D.C., 1980.

National Research Council (NRC): Rethinking the Ozone Problem in Urban and Regional Air Pollution, National Academy Press, Washington D.C., 1991.

Neftel, A., Spirig, C., Prévôt, A. S. H., Furger, M., Stutz, J., Vogel, B., and Hjorth, J.: Sensitivity of photooxidant production in the Milan Basin: An overview of results from a EUROTRAC-2 Limitation of Oxidant Production field experiment, J. Geophys. Res., 107(D22), 8188, doi:10.1029/2001JD001263, 2002.

Pätz, H. W., Corsmeier, U., Glaser, K., Vogt, U., Kalthoff, N., Klemp, D., Kolahgar, B., Lerner, A., Neininger, B., Schmitz, T., Schultz, M. G., Slemr, J., and Volz-Thomas, A.: Measurements of trace gases and photolysis frequencies during SLOPE96 and a coarse estimate of the local $\mathrm{OH}$ concentration from $\mathrm{HNO}_{3}$ formation, J. Geophys. Res., 105, 1563-1583, 2000.

Platt, U.: Air monitoring by Differential Optical Absorption Spectroscopy (DOAS), in: Air Monitoring by Spectroscopic Techniques, edited by: Sigrist, M. W., Chemical Analysis Series, vol. 127, John Wiley \& Sons, Inc., 1994. 
Pope, F. D., Smith, C. A., Ashfold, M. N. R., and Orr-Ewing, A. J.: High-resolution absorption cross sections of formaldehyde at wavelengths from 313 to $320 \mathrm{~nm}$, Phys. Chem. Chem. Phys., 7, 79-84, 2005.

Possanzini, M., Di Palo, V., and Cecinato, A.: Sources and photodecomposition of formaldehyde and acetaldehyde in Rome ambient air, Atmos. Environ., 36, 3195-3201, 2002.

Press, W. H., Teukolsky, S. A., Vetterling, W. T., and Flannery, B. P.: Straight-Line Data with Errors in Both Coordinates, in: Numerical Recipes in C, The Art of Scientific Computing, Cambridge University Press, 1992.

Rembges, D., Fantecchi, G., Dutaur, L., and Brun, C.: AIRMON Annual Report, European Commission, EUR 19665 EN, 1999.

Riggs, D. S., Guarnieri, J. A., and Addelman, S.: Fitting straight lines when both variables are subject to error, Life Sciences, 22, 1305-1360, 1978.

Ritz, D., Hausmann, M., and Platt, U.: An improved open-path multireflection cell for the measurement of $\mathrm{NO}_{2}$ and $\mathrm{NO}_{3}$, in: Optical methods in atmospheric chemistry, edited by: Schiff, H. I. and Platt, U., SPIE Proceedings, 1715, 200-211, 1993.

Rogers, J. D.: Ultraviolet Absorption Cross Sections and Atmospheric Photodissociation Rate Constants of Formaldehyde, J. Phys. Chem., 94, 4011-4015, 1990.

Rothman, L. S., Gamache, R. R., Goldman, A., Brown, L. R., Toth, R. A., Pickett, H. M., Poynter, R. L., Flaud, J. M., Camy-Peyret, C., Barbe, A., Husson, N., Rinsland, C. P., and Smith, M. A. H.: The HITRAN database: 1986, Appl. Opt., 26, 4058-4097, 1987.

Sander, S. P., Kurylo, M. J., Orkin, V. L., et al.: Chemical Kinetics and Photochemical Data for Use in Atmospheric Studies, NASA Panel for Data Evaluation, JPL Publication 02-25, 2003.
Stutz, J.: Messung der Konzentration troposphärischer Spurenstoffe mittels Differentieller Optischer Absorptionsspektroskopie: Eine neue Generation von Geräten und Algorithmen, $\mathrm{PhD}$ thesis, Univ. Heidelberg, 1996.

Stutz, J. and Platt, U.: Numerical analysis and estimation of the statistical error of differential optical absorption spectroscopy measurements with least-squares methods, Appl. Opt., 35, 30, 60416053, 1996.

Tanner, R. L. and Meng, Z.: Seasonal Variations in Ambient Levels of Formaldehyde and Acetaldehyde, Environ. Sci. Technol., 18, 723-726, 1984.

Trapp, D. and de Serves, C.: Intercomparison of Formaldehyde Measurements in the tropical Atmosphere, Atmos. Environ., 29, 3239-3243, 1995.

Vairavamurthy, A., Roberts, J. M., and Newman, L.: Methods for Determination of Low Molecular Weight Carbonyl Compounds in the Atmosphere: A Review, Atmos. Environ., 26A, 11, 19651993, 1992.

Volkamer, R., Junkermann, W., Wirtz, K., and Platt, U.: Formation of Formaldehyde, Glyoxal and Methylglyoxal from the Toluene $+\mathrm{OH}$ reaction in the presence of $\mathrm{NO}_{\mathrm{x}}$, poster presented at EGS XXVII General Assembly, Nice, France, 21-26 April, 2002.

Volz-Thomas, A., Geiss, H., Hofzumahaus, A., and Becker, K. H.: Introduction to Special Section: Photochemistry Experiment in BERLIOZ, J. Geophys. Res., 108(D4), 8252, doi:10.1029/2001JD002029, 2003.

White, J. U.: Very Long Optical Paths in Air, J. Opt. Soc. Am., 66, 411-416, 1976.

York, D.: Least-square fitting of a straight line, Can. J. Phys., 44, 1079-1086, 1966. 